\title{
Structure, Plastic Deformation of Polyethylene: A Molecular Dynamics Method
}

\section{Dung Nguyen Trong1*, Tuan Tran Quoc ${ }^{2}$, Hue Dang Thi Minh ${ }^{3}$, Cuong Nguyen Chinh ${ }^{1}$, Van Duong Quoc ${ }^{1}$}

${ }^{1}$ Faculty of Physics, Hanoi National University of Education, Ha Noi, Vietnam

${ }^{2}$ Faculty of Basic Science, University of Transport Technology, Ha Noi, Vietnam

${ }^{3}$ Faculty of Electrical and Electronics Engineering, Thuyloi University, Ha Noi, Vietnam

Email: *dungntsphn@gmail.com

How to cite this paper: Trong, D.N., Quoc, T.T., Minh, H.D.T., Chinh, C.N. and Quoc, V.D. (2020) Structure, Plastic Deformation of Polyethylene: A Molecular Dynamics Method. Advances in Materials Physics and Chemistry, 10, 125-150. https://doi.org/10.4236/ampc.2020.106010

Received: April 19, 2020

Accepted: June 27, 2020

Published: June 30, 2020

Copyright $\odot 2020$ by author(s) and Scientific Research Publishing Inc. This work is licensed under the Creative Commons Attribution International License (CC BY 4.0).

http://creativecommons.org/licenses/by/4.0/

(c) (i) Open Access

\begin{abstract}
This paper studies the influence factors of atoms number $(\mathrm{N})$ at temperature $(\mathrm{T})$ and after annealing time $(\mathrm{t})$ on the structure shape and the plastic deformation of Polyethylene $\mathrm{C}_{2} \mathrm{H}_{4}$ (PE) by the Molecular Dynamics (MD) method with Dreading pair interaction, cyclic boundary conditions and plastic deformation of Polyethylene (PE) be done by stretching method according to the z-axis. The results of structure, plastic deformation of PE are analyzed through size (l), the total energy of the system $\left(\mathrm{E}_{\text {tot }}\right)$, shape and associated energy $\left(E_{\text {bond }}\right)$, angular binding energy $\left(E_{\text {angle }}\right)$, energy $E_{\text {dihedral }}$, interactive energy Vander Walls $\left(E_{\text {non-bonding }}\right)$. When increasing $N$, $t$ leads to the number of structural units of Face-Centred Cubic (FCC), Body-Centered Cubic (BCC) and Hexagonal Close-Packed (HCP) increasing, but Amorphous (Amor) decreases while the angle between the atoms is a constant corresponding to $109.5^{\circ}$. Besides, the length of the link ( $r$ ) increases from $r=1.529$ $\AA$ to $\mathrm{r}=1.558 \AA$ while the plastic deformation energy of PE gets an enormous change and the bonding angle at $109.27^{\circ}$. The length of the link $r=1.529 \AA$ and the size (l) of the PE material increase from $1=3.73 \mathrm{~nm}$ to $l=6.63 \mathrm{~nm}$ while the total energy of system $\left(\mathrm{E}_{\text {total }}\right)$ decreases from $\mathrm{E}_{\text {total }}=-1586 \mathrm{eV}$ to $\mathrm{E}_{\text {total }}$ $=-7891 \mathrm{eV}$ with the transition temperature is $\mathrm{T}=103 \mathrm{~K}$. Increasing the number of atoms leads to increasing the length of the link. The total energy $\mathrm{E}_{\text {total }}$ of the system decreases, but the number of structural units in FCC, HCP, BCC and Amor increase, which leads to the length of the link increases, the $\mathrm{E}_{\text {total }}$ decreases, and there is a change in the plastic deformation characteristics of PE. In contrast, increasing $\mathrm{T}$ leads to the plastic deformation increases, and PE moves from the amorphous state to the liquid state. The obtained results are very significant for future experimental research.
\end{abstract}




\section{Keywords}

Molecular Dynamics, Atoms Number, Annealing Time, Polyethylene, Plastic Deformation

\section{Introduction}

Polyethylene $\mathrm{C}_{2} \mathrm{H}_{4}$ (PE) is a flexible plastic existing in an amorphous state and widely used in consumer products. In particular, PE plays an important role in material science, which is considered as a bright candidate for new industrial materials. When PE is combined with wood, it creates an environmentally Wood Plastic Composite material (WPC) [1] [2] such as reducing energy consumption in production, lightweight, and sound insulation [3] [4] [5]; reducing pollution and greenhouse effect; enhancing biodegradability [6] [7] [8]. Also, WPC is widely used in industries such as automotive, construction, et al. [6] [9]. The flexible plastic resins are made of Polyethylene (PE) [8], Polypropylen [10], Polyvinyl Clorua (PVC) [11] and polystyrene (PS) [12]. The Wood components include wood pulp, cotton, wheat straw, bagasse, and rice husk [13] [14] [15] [16] [17]. PE plastic is used in practice including both High-Density Polyethylene (HDPE) and low-density WPC [18]. PE, as a binder and wood pulp as an additive; HDPE includes material hydrophilic wood pulp and PE hydrophobic wood pulp [19] [20]. Therefore, PE is considered as an important additive component in industrial applications. PE is divided into many types, mainly based on density, monomer, flexibility [21], and copolymer [22] [23] [24]. In particular, with Low-Density Polyethylene (LDPE) which is the most commonly used and commercially produced at high pressure $(\mathrm{P}), \mathrm{P}=2400 \mathrm{Bar}$, temperature $(\mathrm{T})$ from $\mathrm{T}=$ $363 \mathrm{~K}$ to $\mathrm{T}=383 \mathrm{~K}[25]$.

To study this material, it is good to use the experimental, theoretical, and simulation methods. As for the experimental method, using pressing methods and multi-layer extrusion method with low cost has high durability, ductility [26] and increasing stress [27] [28] as Jatin et al. [29], Kurz et al. [30], Pouriayevali et al. [31] for that plastic deformation of $\mathrm{PE}$ is an isotropic function with pressure putting on (the deformation $(\varepsilon)$ in the experiment which is always less than $\varepsilon<$ 0.12); Epee et al. [32] suggested that the deformation of the polymer with $\varepsilon<800$ $\mathrm{s}^{-1}$; Argon et al. [33] suggested that plastic deformation is due to the twisted bonding pairs along the polymer chain; Roberson suggested that the shear stress is caused by changing angles and movements of molecules [2]; Eyring et al. [1] suggested that the plastic deformation is caused by the shear stress, structural changing, and binding energy [34]-[40]. With the simulation method, Deng et al. [41] suggested that plastic deformation is caused by the local structure. Besides, Maeda, Takeuchi [42], Srolovitz et al. [43] successfully used the molecular statistical method (MS) to study the deformation of three-dimensional metal glasses; Theodorou and Suter [44] [45] successfully simulated the material in the 
glass polymer material and studied the deformation. After that, MS. Mott et al. [46], Hutnick et al. [47] used this method to study the plastic deformation of Polypropylene and Polycarbonate. While Mott et al. suggested that the plastic deformation is the result of changing the displacement in atoms or molecular branches, Hutnick et al. suggested that the movement of atoms does not depend on chemical reactions. Similarly, Brown, Clarke [48], Mckechnie, and Clarke [49] successfully investigated the effect of temperature on the bond in glass polyethylene and mechanics of materials. It is said that increasing the plastic deformation and the length of the initial link is necessary. Although there have been many studies on the plastic deformation of PE in the static state or the dynamic state [48] [50]-[57] such as Baltsas et al. [58], Haefele et al. [59], using simulation method with Low-Density Polyethylene (LDPE) at high pressure; Asteasuain et al. [60] use Graphical Optimization Tool (gOPT) of general PROcess Modelling System (gPROMS) simulator program to optimize LDPE; Bezzo et al. [61] successfully used Fluent, gPROMS for liquids by calculating molecular dynamics. Recently, Clarke [48] has successfully performed uniaxial deformation of amorphous Polymers with different deformation levels at low temperatures, which is obtained in qualitative form. Capaldi et al. [42] suggested that the compressive deformation of Polymer is the same as the change of angle, the angle shift along the chain; Li et al. [62] successfully performed Single-axis plastic deformation of Polyethylene (PE) amorphous by Monte Carlo method (MC) with FCC structure and bonding length $(\mathrm{r}), \mathrm{r}=1.53 \AA$. The result shows that there is a dependence on temperature $(\mathrm{T})$, and the heating rate and Uniaxial Tension of the material [63]; Ospina et al. [64] using the MC simulation result of the initial plastic deformation stage of polyethylene gives the consistent result with the experimental result, and it does not reduce the plastic deformation [63] [64] [65]; factors that alter the structure of $\mathrm{PE}$ [66] [67] as concentrations of impurities playing an important role in compounds [67] [68].

The result shows that the phase transition of Polyethylene depends on the temperature [69] [70] [71] as the liquefaction process which is just below the room temperature $\mathrm{T}=300 \mathrm{~K}$, limited by the movement of atoms at transition layer between the crystal area and the amorphous region. This shift occurs very weakly in HDPE with temperature from $\mathrm{T}=123 \mathrm{~K}$ to $\mathrm{T}=173 \mathrm{~K}$ and it is linked with the movement of $\mathrm{CH}_{2}$ groups attached to $\mathrm{C}_{2} \mathrm{H}_{4}$ [72], the change in the molecular shape of the polymer depends on the relationship between temperature and pressure [73]; the phase transition depends on the heating rate, the total energy of the system during the deformation process [74]. The results show that the glass transition temperature $\left(\mathrm{T}_{\mathrm{g}}\right)$ depends on the movement of atoms with valuable in approx from $\mathrm{T}_{\mathrm{g}}=133 \mathrm{~K}$ to $\mathrm{T}_{\mathrm{m}}=408 \mathrm{~K}$ [75], and this is performed on experimental measurements [76].

Besides, many authors have successfully studied the plastic deformation of PE by the $\mathrm{z}$-axis stretching method. The results show the influence of the chain length, the number of chains, the strain rate, and the temperature. This depends 
on the stress-strain [77] [78] [79] [80] which is ended at the source of plastic deformation. Polyethylene is a problem that has not been explained in detail [81]. To solve the problem, we focus on studying the effect of atomic number, temperature, annealing time on the structure, and the plastic deformation of PE.

\section{Method of Calculation}

Initially, randomly sow atomic number $(\mathrm{N}), \mathrm{N}=2000$ atoms, 4000 atoms, 6000 atoms, 8000 atoms, 10,000 atoms Polyethylene $\left(\mathrm{C}_{2} \mathrm{H}_{4}\right.$ or $\left.\mathrm{PE}\right)$ into the cube by the Molecular Dynamics (MD) method [42] [44] [82] [83] Dreading pair interaction (1), cyclic boundary conditions [42] [84] [85] [86] [87] [88] through the total energy of the system $\left(E_{\text {tot }}\right): E_{\text {tot }}=E_{\text {bond }}+E_{\text {angle }}+E_{\text {dihedral }}+E_{\text {non-bonding }}(1)$.

In it:

$$
\begin{aligned}
& \mathrm{E}_{\text {bond }}(\mathrm{r})=\frac{1}{2} \mathrm{~K}_{\mathrm{b}}\left(\mathrm{r}-\mathrm{r}_{0}\right)^{2}, \\
& \mathrm{E}_{\text {dihedral }}(\varphi)=\sum_{\mathrm{i}=0}^{3} \mathrm{C}_{\mathrm{i}}(\cos \varphi)^{\mathrm{i}}, \\
& \mathrm{E}_{\text {angle }}(\theta)=\frac{1}{2} \mathrm{~K}_{\theta}\left(\theta-\theta_{0}\right)^{2}, \\
& \mathrm{E}_{\text {non-bonding }}(\mathrm{r})=4 \varepsilon\left[\left(\frac{\sigma}{\mathrm{r}}\right)^{12}-\left(\frac{\sigma}{\mathrm{r}}\right)^{6}\right], \mathrm{r} \leq \mathrm{r}_{\mathrm{c}}
\end{aligned}
$$

With: $E_{\text {bond }}$ is the bond energy, $E_{\text {angle }}$ is the bond angle energy, the $E_{\text {dihedral }}$ is dihedral energy, $E_{\text {non-bonding }}$ is van der Waals energy in the Lennard-Jones interaction, $E_{\text {tot }}$ is the total energy of the system, $\mathrm{K}_{\mathrm{b}}=350 \mathrm{kcal} / \mathrm{mol}, \mathrm{K}_{\theta}=60 \mathrm{kcal} / \mathrm{mol} \cdot \mathrm{rad}^{2}$ is the stiffness coefficient, the bond angle coefficient, $\mathrm{r}_{0}=1.53 \AA$ is the bond length, $\theta_{0}=1.911 \mathrm{rad}\left(109.5^{\circ}\right)$ is the link angle, $\mathrm{C}_{0}=1.736, \mathrm{C}_{1}=-4.490, \mathrm{C}_{2}=0.776, \mathrm{C}_{3}=$ $6.99(\mathrm{kcal} / \mathrm{mol})$ are the coefficients, $\sigma=4.01 \AA$ is the energy at $0 \mathrm{eV}, \varepsilon=0.112$ $\mathrm{kcal} / \mathrm{mol}$ is the dielectric constant, $\mathrm{r}_{\mathrm{c}}=10 \AA$ is the radius interrupt.

After obtaining, all PE samples for running $10^{6}$ steps molecular dynamics (MD) simulation recovery statistics at temperature $(\mathrm{T}), \mathrm{T}=500 \mathrm{~K} ; 10^{6}$ steps NPT (atomic number, pressure, and constant temperature) MD simulation at $\mathrm{T}=500$ $\mathrm{K}$. After obtaining PE samples at $\mathrm{T}=500 \mathrm{~K}$, the samples were lowered from $\mathrm{T}=$ $500 \mathrm{~K}$ to $\mathrm{T}=100 \mathrm{~K}$. Particularly with $\mathrm{N}=10000$ atoms at $\mathrm{T}=500 \mathrm{~K}$, the temperature is lowered to $\mathrm{T}=120 \mathrm{~K}, 100 \mathrm{~K}, 80 \mathrm{~K}, 60 \mathrm{~K}, 40 \mathrm{~K}$. When increasing $\mathrm{t}$, from $\mathrm{t}$ $=0 \mathrm{ps}$ to $\mathrm{t}=50 \mathrm{ps}, 100 \mathrm{ps}, 150 \mathrm{ps}, 200 \mathrm{ps}$ at $\mathrm{T}=100 \mathrm{~K}$. The temperature was set intentionally, which is to study PE material in the crystalline state with temperature the below glass transition temperature $\left(\mathrm{T}_{\mathrm{g}}\right), \mathrm{T}_{\mathrm{g}}=250 \mathrm{~K}$ [89], size (l) of PE material lying in the range from $l=3.73 \mathrm{~nm}$ to $l=6.36 \mathrm{~nm}$, the time for each simulation step is $\Delta t=0.1$ fs. The program code used to run the PE sample that is the open-source program code LAMMPS [90] [91] with the heating rate, which is obeyed following the Nosé-Hoover rule [92] [93] [94], van der Waal link [95] [96] [97] [98] [99]. To study the plastic deformation of PE under the effect of the force in the direction of the $\mathrm{z}$-axis with the constant heating rate at 
pressure $(\mathrm{P}), \mathrm{P}=0 \mathrm{GPa}$ by defining quantities in the direction of the $\mathrm{z}$-axis single tension from the NPT equations of the PE shift process [91]. The stress components are calculated from energy contributions related to the length of the link, bonding angle, bipolar angle, and non-bonding interaction, which are combined with the Common Neighbor Analysis (CNA) method [100] [101] [102] by Ovito software.

\section{Results and Discussion}

\subsection{Effect of Atomic Number}

\subsubsection{The Phase Transition of Polyethylene}

The result of the phase transition Polyethylene $\mathrm{C}_{2} \mathrm{H}_{4}(\mathrm{PE})$ is shown in Figure 1 .

The results show that after running the Recovery Statistics (RS), RS $=10^{6}$ steps of moving the Molecular Dynamics (MD) simulation at the temperature (T), $\mathrm{T}=$ $500 \mathrm{~K}$, then the pressure of the system (P) decreases, with PE 2000 atoms lead to $\mathrm{P}$ decreases from $\mathrm{P}=4464 \mathrm{Bar}$ to $\mathrm{P}=-144 \mathrm{Bar}$. At a steady state, when $\mathrm{N}$ increasing from $\mathrm{N}=2000$ atoms to $\mathrm{N}=10,000$ atoms leads to $\mathrm{P}$ increases from $\mathrm{P}=$ -144 Bar to $\mathrm{P}=292$ Bar (Figure 1(a)). Similarly, with the process of running $10^{6}$ steps NPT (with atoms number, pressures, and temperatures is constant) leads to $\mathrm{P}$ changes on the range from $\mathrm{P}=-558 \mathrm{Bar}$ to $\mathrm{P}=706 \mathrm{Bar}$, with $\mathrm{PE} 10,000$ atoms the $\mathrm{P}$ has the smallest change (Figure $1(\mathrm{~b})$ ). The process of temperature reduction from $\mathrm{T}=500 \mathrm{~K}$ to $\mathrm{T}=100 \mathrm{~K}$ shows that the $\mathrm{P}$ of $\mathrm{PE} 10,000$ atoms has not changed significantly (Figure $1(\mathrm{c})$ ). The energy values of $\mathrm{PE}$ at $\mathrm{T}=100 \mathrm{~K}$ has value corresponding change. The total energy pair $\left(\mathrm{E}_{\text {pair }}\right)$ decreases from $\mathrm{E}_{\text {pair }}$ $=-3014 \mathrm{eV}$ to $\mathrm{E}_{\text {pair }}=-15,161 \mathrm{eV}$ (Figure $1(\mathrm{~d})$ ), the total electron bond energy $\left(\mathrm{E}_{\mathrm{bond}}\right)$ increases from $\mathrm{E}_{\mathrm{bond}}=199 \mathrm{eV}$ to $\mathrm{E}_{\mathrm{bond}}=994 \mathrm{eV}$ (Figure 1(e)), the total angle bond energy $\left(\mathrm{E}_{\text {angle }}\right)$ increases from $\mathrm{E}_{\text {angle }}=223 \mathrm{eV}$ to $\mathrm{E}_{\text {angle }}=1158 \mathrm{eV}$ (Figure 1(f)), the total dihedral energy $\left(\mathrm{E}_{\text {dihed }}\right)$ increases from $\mathrm{E}_{\text {dihed }}=719 \mathrm{eV}$ to $\mathrm{E}_{\text {dihed }}=3544 \mathrm{eV}$ (Figure $1(\mathrm{~g})$ ) and $\mathrm{E}_{\text {tot }}$ decreases from $\mathrm{E}_{\text {tot }}=-1873 \mathrm{eV}$ to $\mathrm{E}_{\text {tot }}=$ $-9465 \mathrm{eV}$ (Figure 1(h)). Basing on the given result, after $10^{6}$ steps moving of recovering statistics, then PE reached equilibrium; $10^{6}$ steps moving NPT at temperature $(\mathrm{T}), \mathrm{T}=500 \mathrm{~K}$ lead to $\mathrm{PE}$ existed in a liquid state. When the temperature decreases from $\mathrm{T}=500 \mathrm{~K}$ to $\mathrm{T}=100 \mathrm{~K}$ leading to $\mathrm{PE}$ changes from the liquid state to a new crystalline state, running stably $10^{6}$ steps NPT at $\mathrm{T}=100 \mathrm{~K}$ obtained PE in the new crystalline state corresponds to the shape of PE (Figure $1(\mathrm{i})$ ). As a result, when increasing atoms number (N) leads to the size (l) increases, but $\mathrm{E}_{\text {tot }}$ decreases.

\subsubsection{Plastic Deformation Process of Polyethylene}

The results of the plastic deformation process of Polyethylene (PE) at temperature $(\mathrm{T}), \mathrm{T}=100 \mathrm{~K}$ are shown in Figure 2, Table 1.

The obtained result shows that after the process of the temperature reduction from $\mathrm{T}=500 \mathrm{~K}$ down to $\mathrm{T}=100 \mathrm{~K}$ with $10^{6}$ step $\mathrm{MD}$ simulation, the 


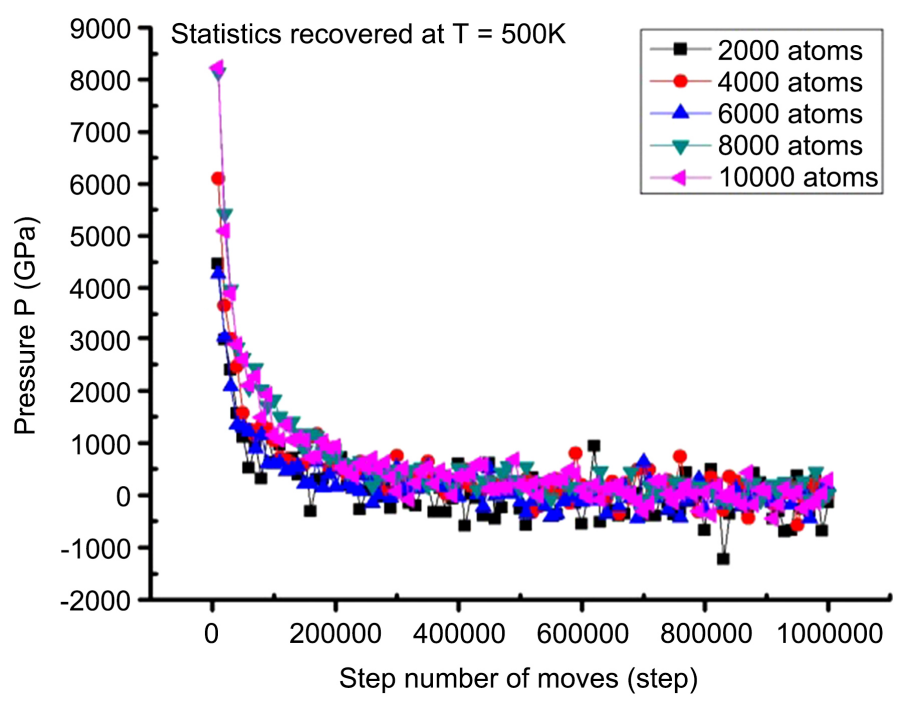

(a)

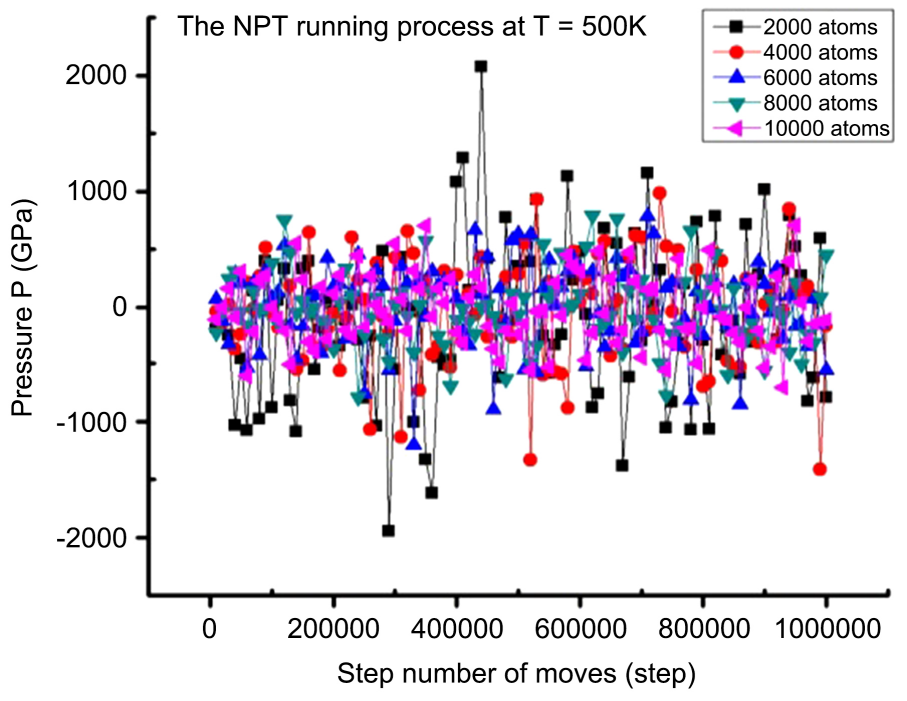

(b)

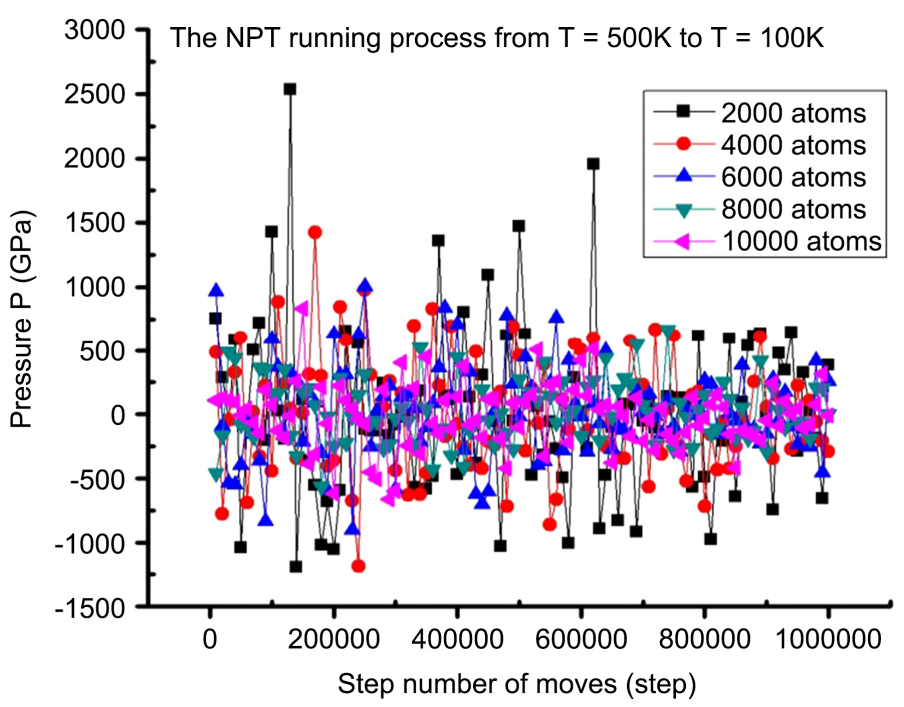

(c) 


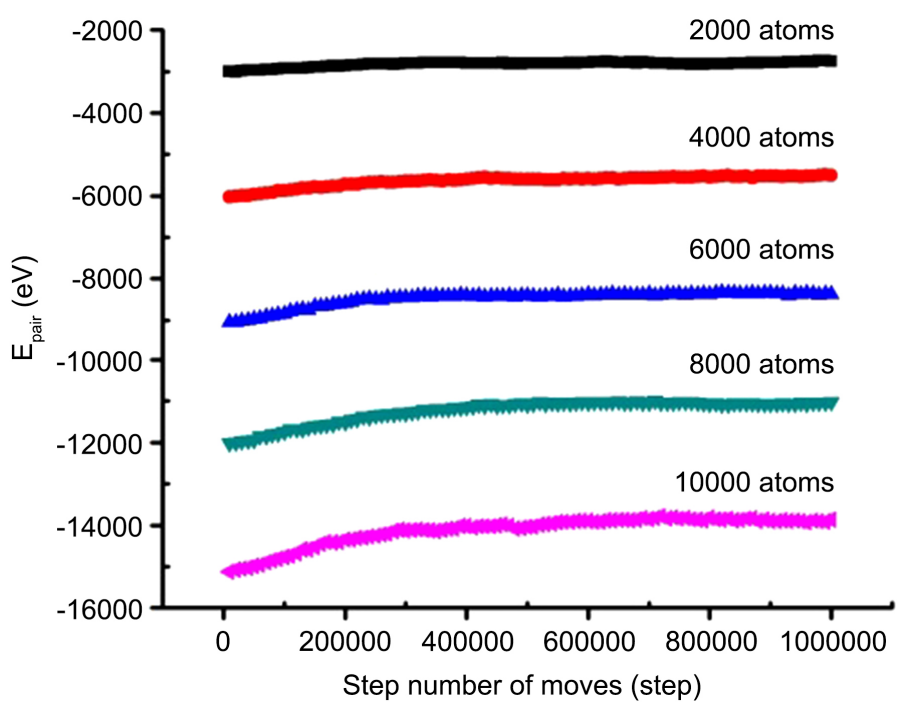

(d)

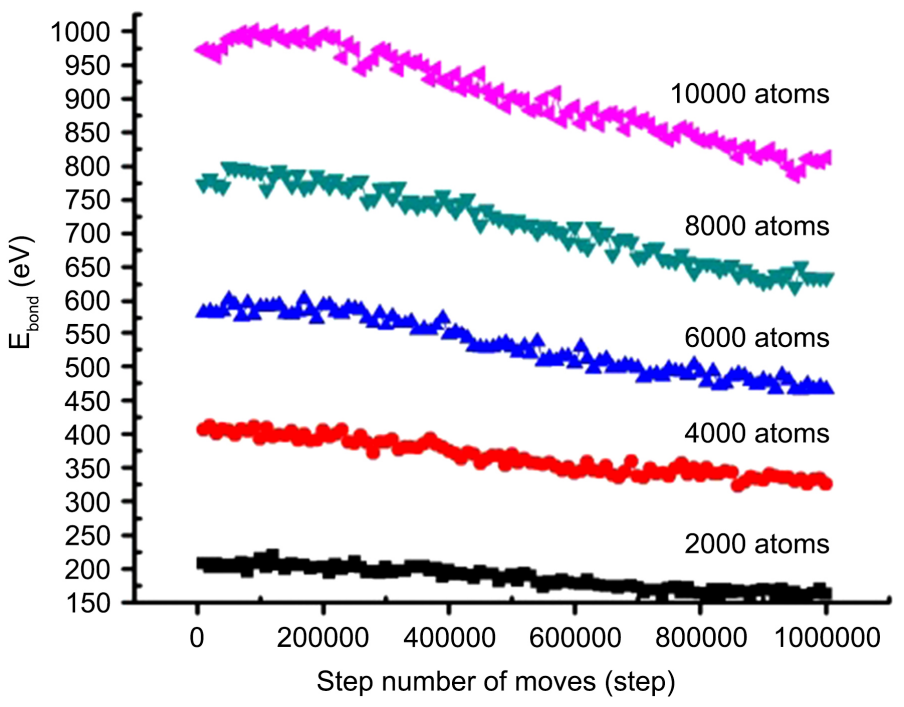

(e)

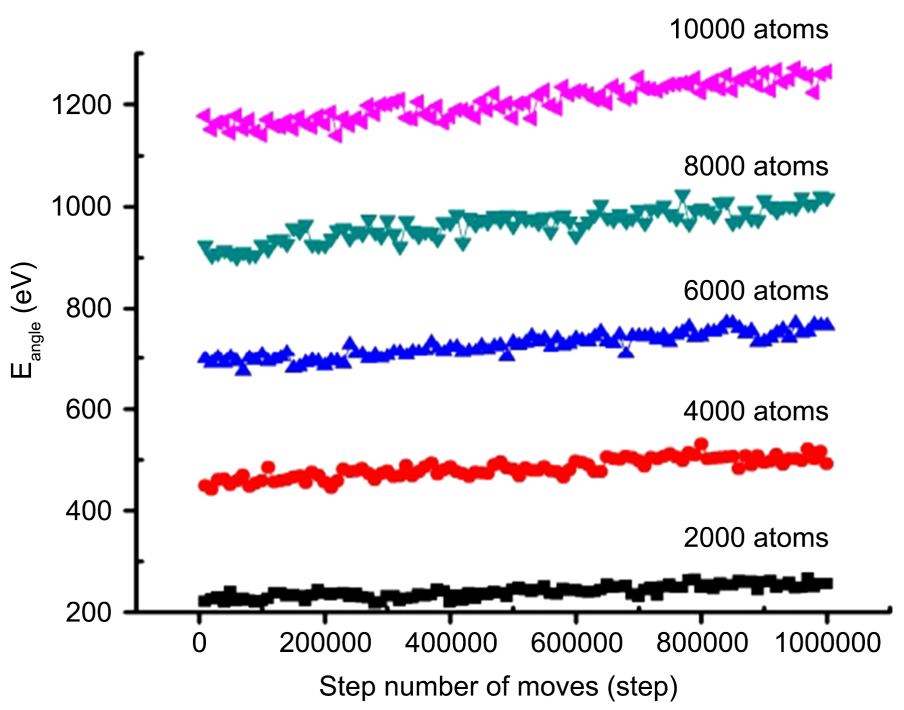

(f) 


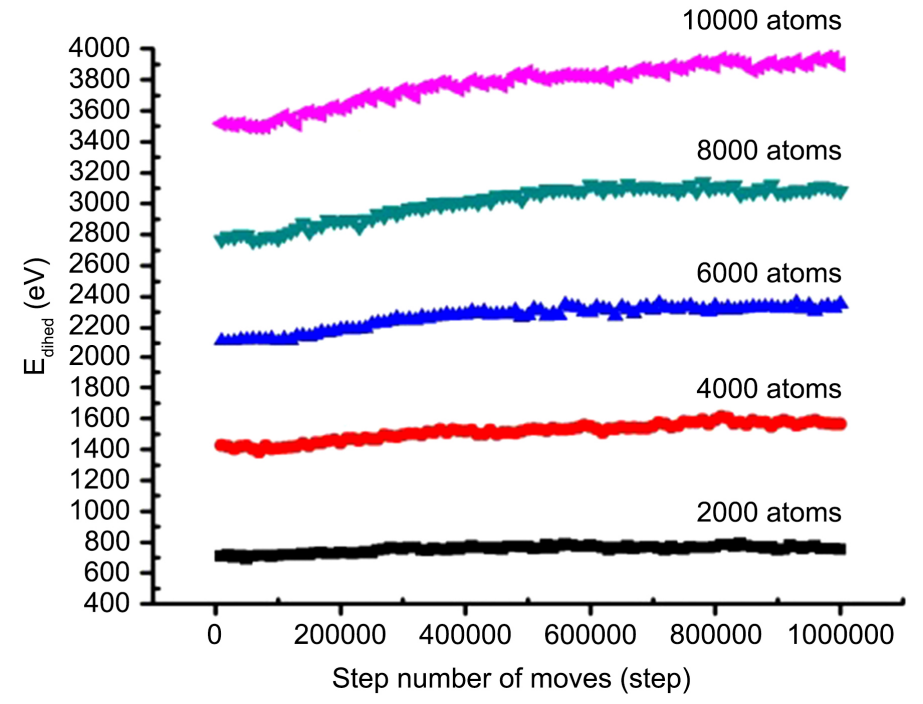

(g)

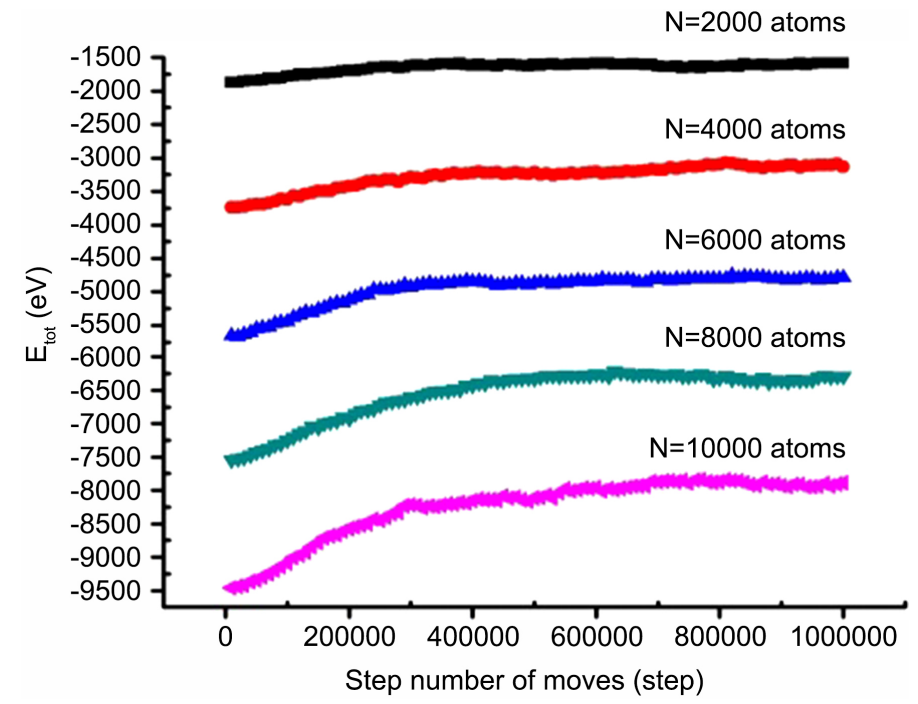

(h)

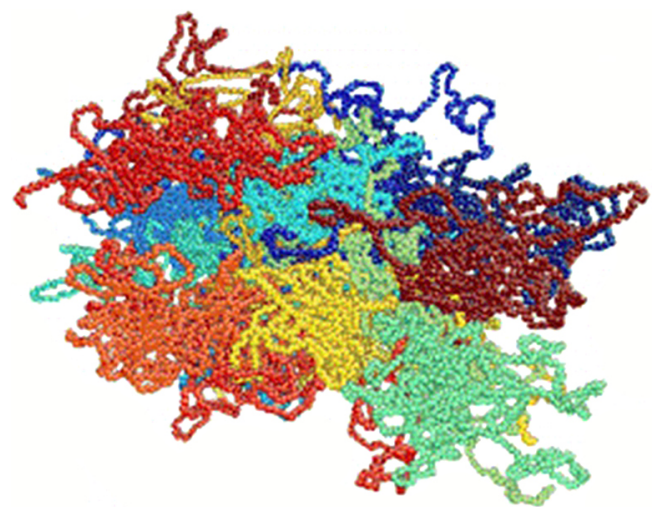

(i)

Figure 1. The phase transition of polyethylene after $10^{6}$ steps recovery statistics at the temperature at $500 \mathrm{~K}(\mathrm{a}), 10^{6}$ steps of NPT at the temperature $500 \mathrm{~K}(\mathrm{~b}), 10^{6}$ steps to the lower temperature from $500 \mathrm{~K}$ down to $100 \mathrm{~K}$ (c), the energy values (d)-(h), and the shape of the PE (i) with atomic number, the number of different displacement steps. 
Table 1. The process of transforming the number of structural units after the number of different MD shift steps.

\begin{tabular}{ccccccc}
\hline Shift step number (step) & 0 & $2 \times 10^{5}$ & $4 \times 10^{5}$ & $6 \times 10^{5}$ & $8 \times 10^{5}$ & $10 \times 10^{5}$ \\
\hline FCC & 4 & 15 & 13 & 13 & 5 & 12 \\
HCP & 56 & 55 & 54 & 58 & 47 & 60 \\
BCC & 2 & 4 & 1 & 7 & 9 & 6 \\
Amor & 1938 & 1926 & 1932 & 1922 & 1939 & 1922 \\
\hline
\end{tabular}

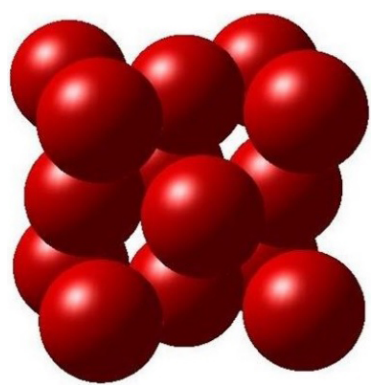

(a)

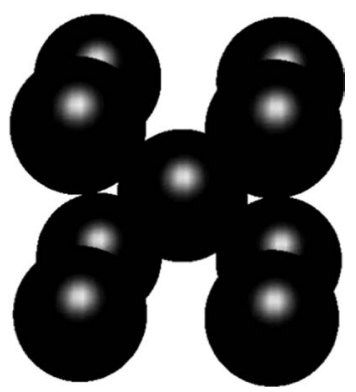

(c)

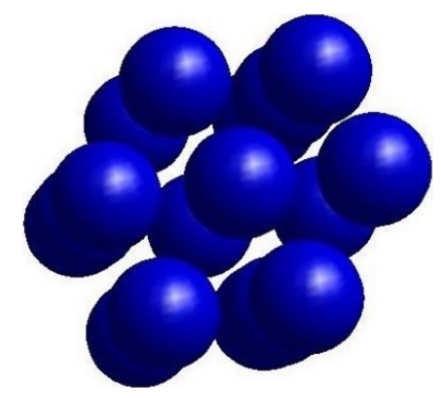

(b)

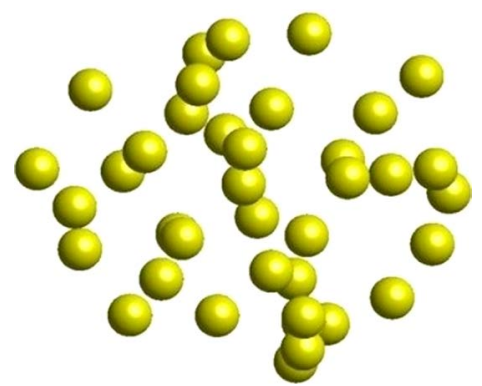

(d)

Figure 2. The structural unit number shapes of Polyethylene as FCC structure (a), HCP structure (b), BCC structure (c), Amor structure (d).

polyethylene has a cube shape (Figure 2(a)-(d)) with the number of structural units is 4 FCC, 56 HCP, 2 BCC, 1938 Amor (Table 1). When increasing moving the number of steps from 0 to $10^{6}$ of the MD simulation leading to PE changing from the cube shape to the rectangular box shape (Figures 3(a)-(f)), and the of number structural units of FCC, HCP, BCC, Amor changes corresponding (Table 1). When increasing moving the number of steps of the MD leading to the number of structural units unchanged. Particularly, the shape has a huge change raising the question after compressing the PE time of the z-axis, the PE's shape has changed leading to changing the plastic deformation characteristics of the PE. To confirm that studying the plastic deformation characteristics with different moving the number of steps, the results shown in Figure 4, Table 2.

The results show that the number of structural units with the atomic number $(\mathrm{N}), \mathrm{N}=2000$ atoms is $12 \mathrm{FCC}, 60 \mathrm{HCP}, 6 \mathrm{BCC}$, and the characteristics of the plastic deformation include the bonding energy between atoms, $\mathrm{E}_{\mathrm{bond}}$ which is 
shown by the red color line, $\mathrm{E}_{\text {angle }}$ is angular bond energy shown by the blue color line, the $\mathrm{E}_{\text {dihed }}$ is energy dihedral shown by the blue color line, $\mathrm{E}_{\text {total }}$ shown by the purple color line, (Figure 4(a), Table 2). When increasing $\mathrm{N}$ from $\mathrm{N}=2000$ atoms to $\mathrm{N}=4000$ atoms, 6000 atoms, 8000 atoms and 10,000 atoms leads to the total energy pair $\left(\mathrm{E}_{\text {pair }}\right)$ decreases from $\mathrm{E}_{\text {pair }}=-2756 \mathrm{eV}$ to $\mathrm{E}_{\text {pair }}=-13,866 \mathrm{eV}$ (Figure $4(\mathrm{~b})$ ), energy bond $\left(\mathrm{E}_{\mathrm{bond}}\right)$ increases from $\mathrm{E}_{\mathrm{bond}}=163 \mathrm{eV}$ to $\mathrm{E}_{\mathrm{bond}}=812$ $\mathrm{eV}$ (Figure 4(c)), angular bond energy $\mathrm{E}_{\text {angle }}$ increases from $\mathrm{E}_{\text {angle }}=256 \mathrm{eV}$ to $\mathrm{E}_{\text {angle }}=1264 \mathrm{eV}$ (Figure 4(d)), the energy dihedral increases from $\mathrm{E}_{\text {dihed }}=751 \mathrm{eV}$ to $\mathrm{E}_{\text {dihed }}=3899 \mathrm{eV}$ (Figure 4(e)), and $\mathrm{E}_{\text {total }}$ decreases from $\mathrm{E}_{\text {total }}=-1586 \mathrm{eV}$ to $E_{\text {total }}=-7891 \mathrm{eV}$ (Figure 4(f)), free volume change the number of atoms (Figure $4(\mathrm{~g})$ ), the plastic deformation process of PE (Figure $4(\mathrm{~h})$ ), the PE shape (Figure 4 (i)) after deformation at $\mathrm{T}=100 \mathrm{~K}$, and the number of structural units of FCC

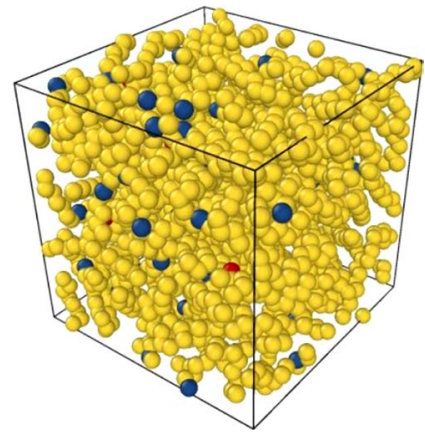

(a)

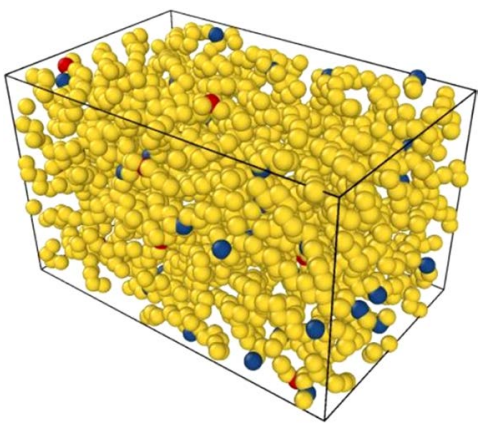

(c)

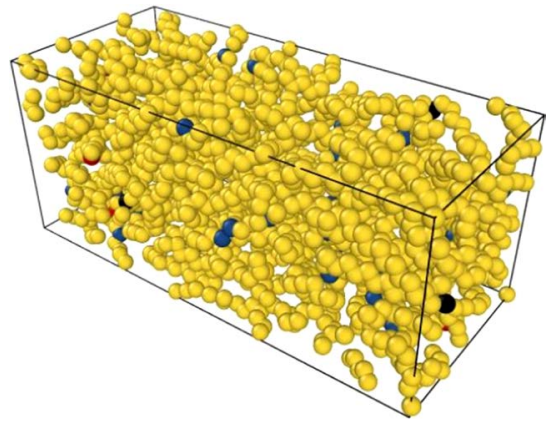

(e)

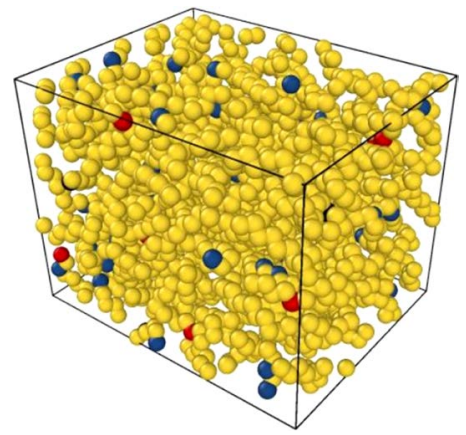

(b)

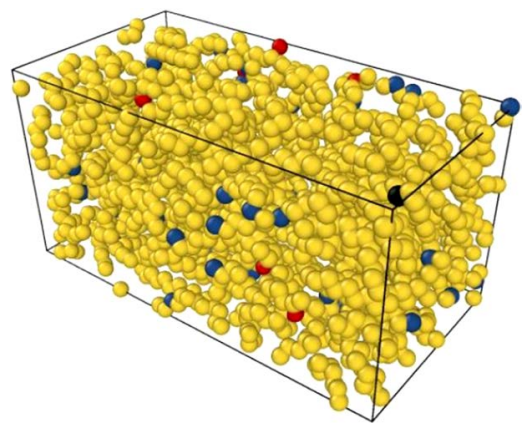

(d)

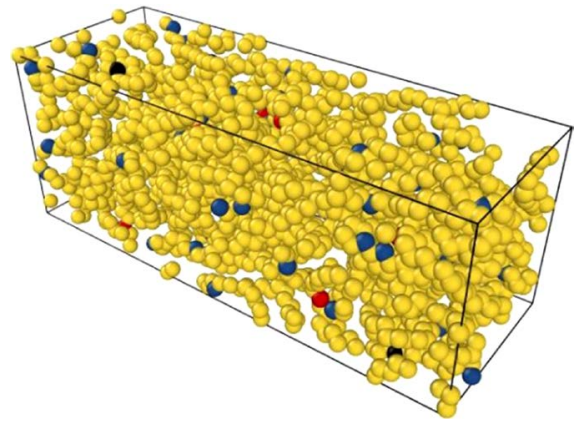

(f)

Figure 3. The PE structure shape of PE with the different number of MD shift steps: In the initial state (a), after $2 \times 10^{5}$ steps MD (b), $4 \times 10^{5}$ steps MD (c), $6 \times 10^{5}$ steps MD (d), $8 \times 10^{5}$ steps MD (e), $10^{6}$ steps MD (f). 


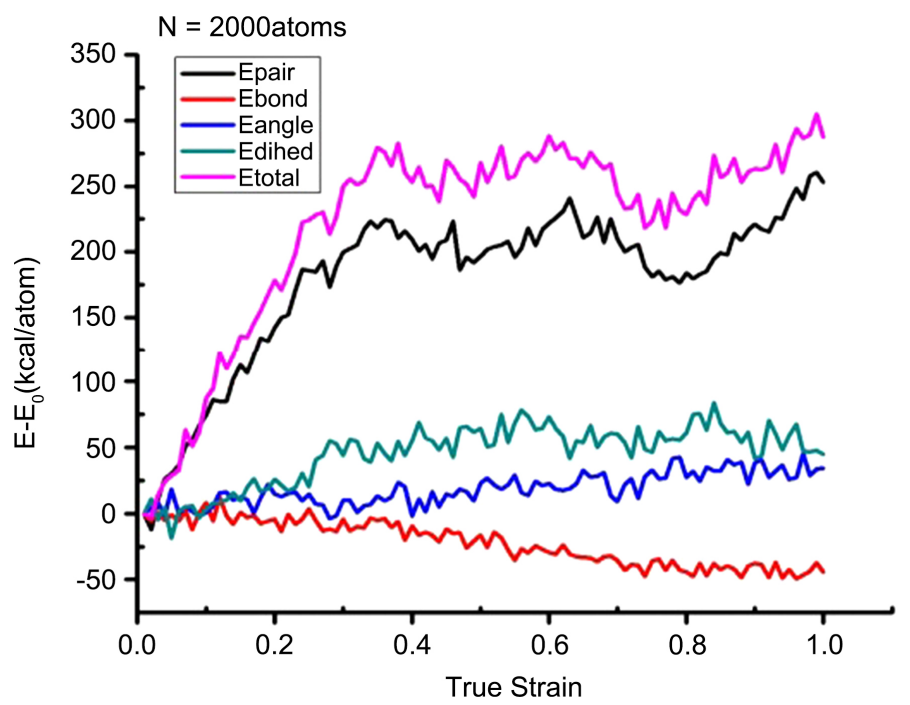

(a)

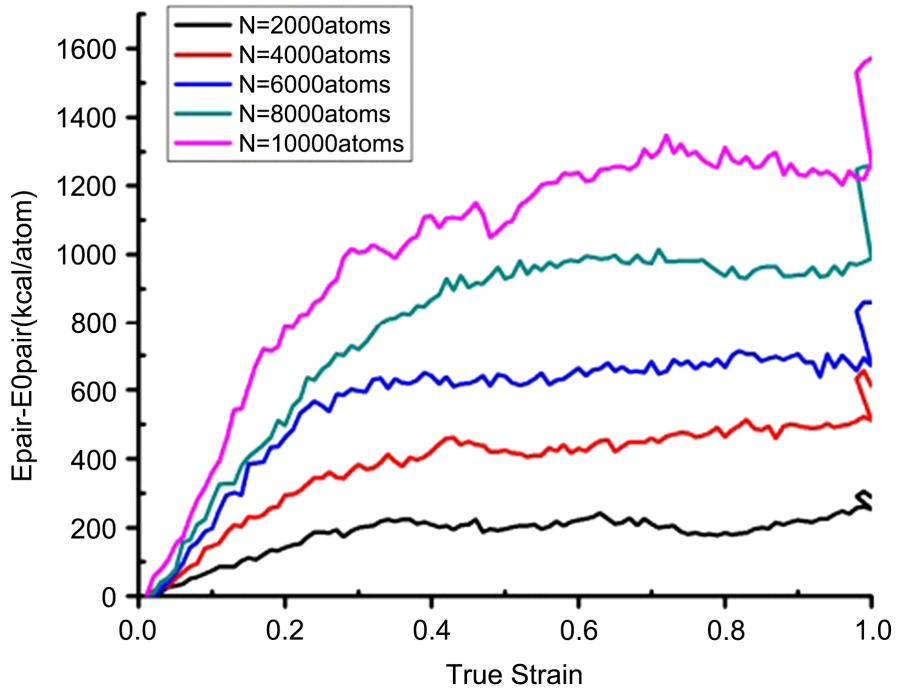

(b)

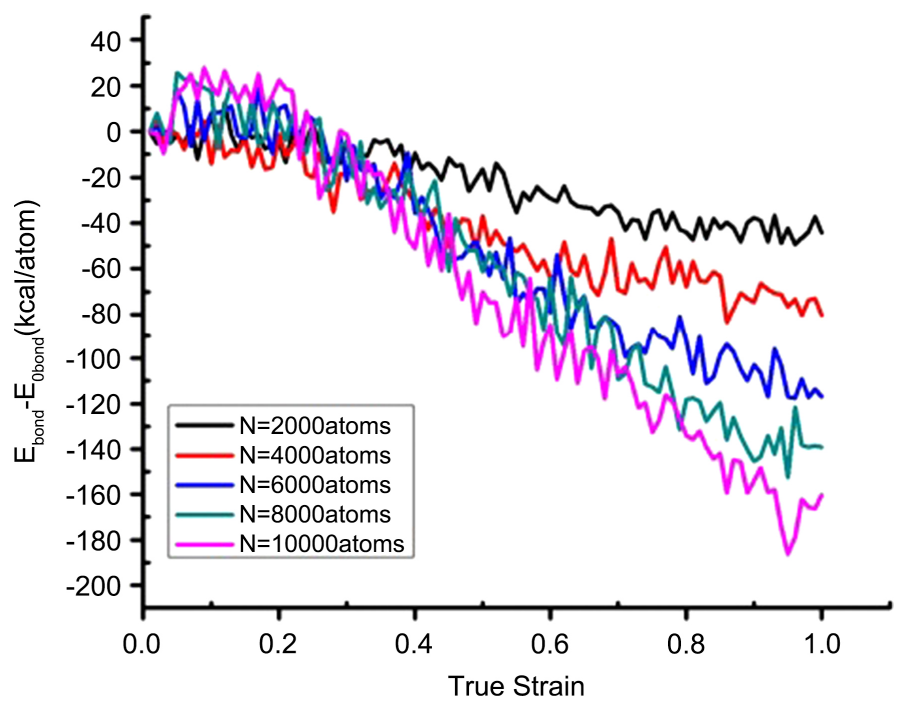

(c) 


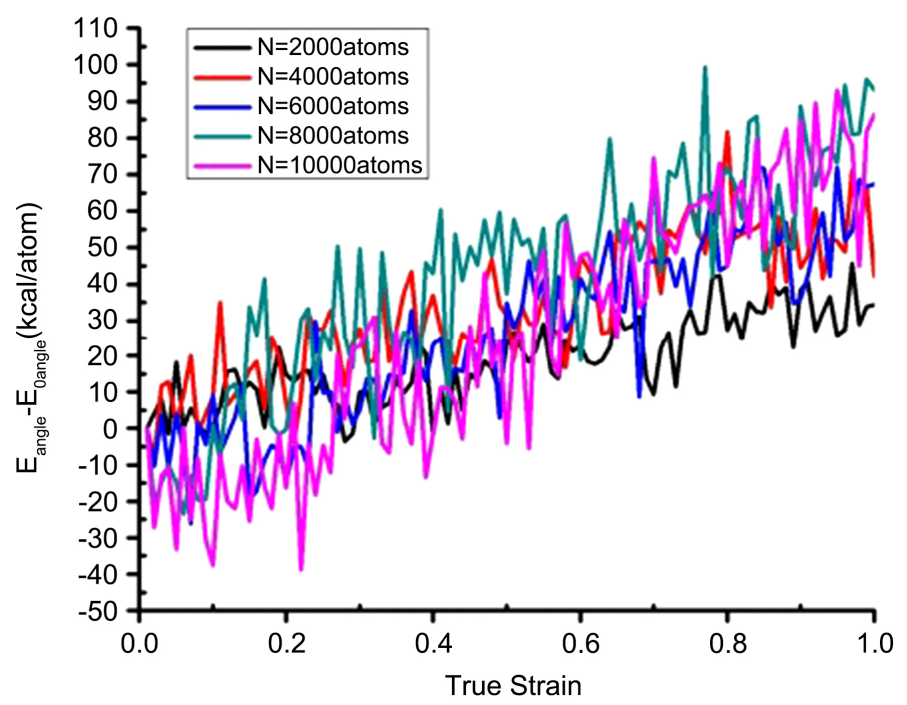

(d)

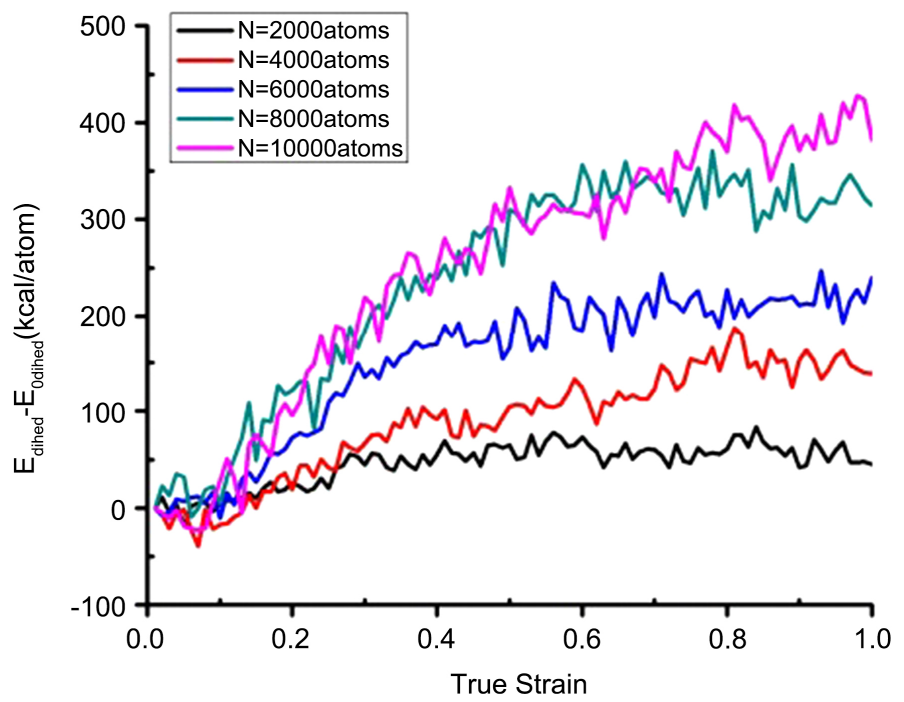

(e)

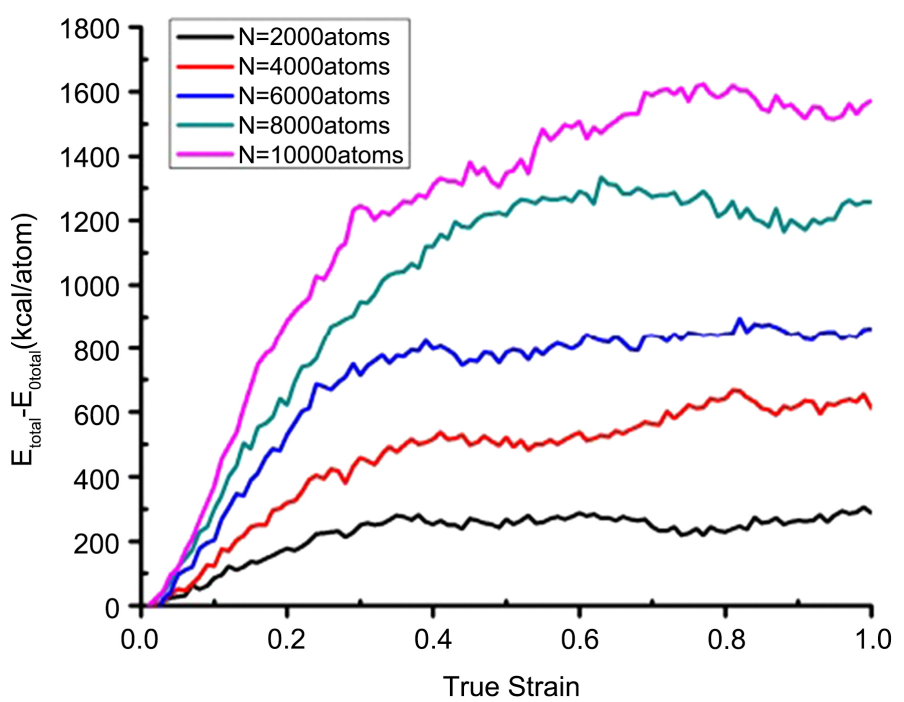

(f) 


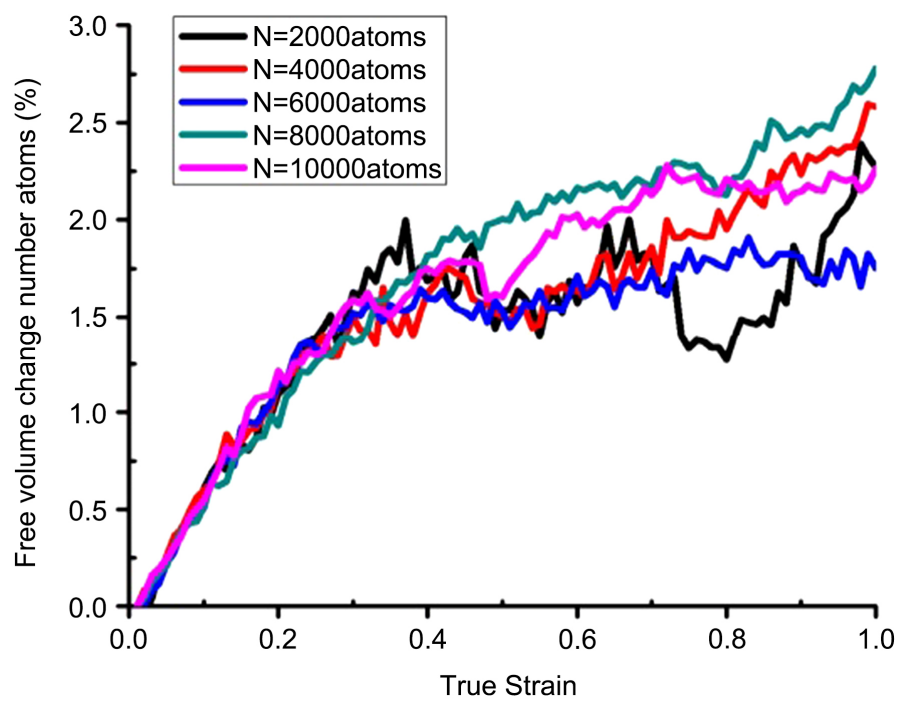

(g)

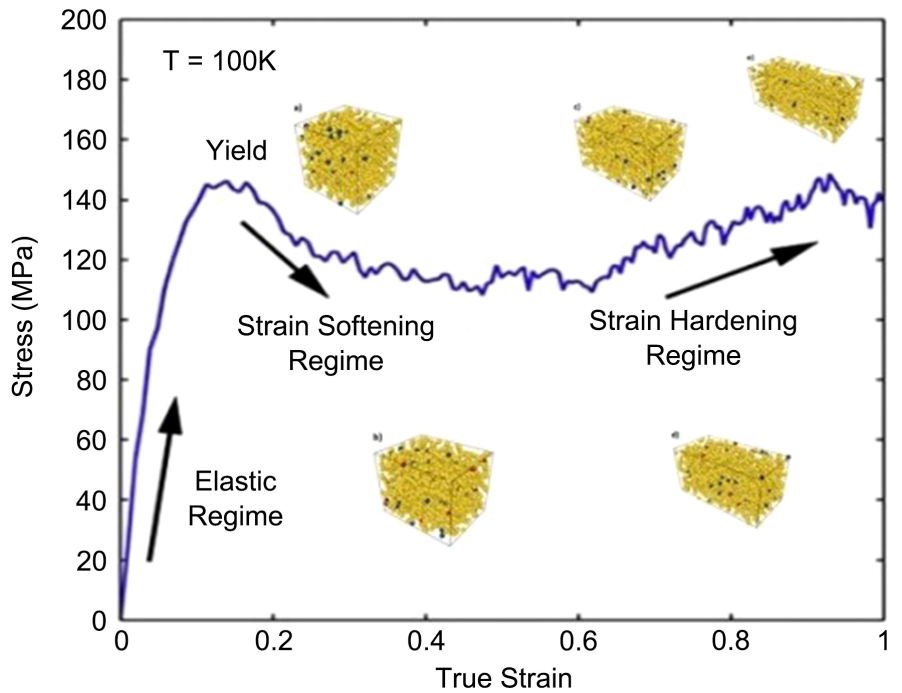

(h)

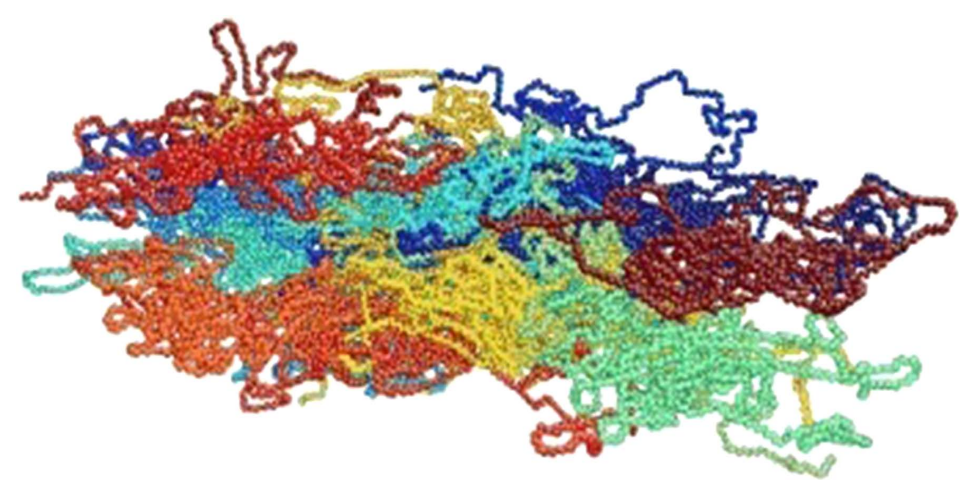

(i)

Figure 4. The plastic deformation process as the energy $\mathrm{E}$ (a), the total energy pair $\mathrm{E}_{\text {pair }}$ (b), the total electron bond energy $E_{\text {bond }}(c)$, the total energy angle $E_{\text {angle }}(d)$, the total dihedral energy $E_{\text {dihed }}(e)$, the total energy $E_{\text {tot }}(f)$, free volume change the number of atoms (g), stress (h), the PE shape (i) after deformation at $\mathrm{T}=100 \mathrm{~K}$ with atomic number and different moving the number of steps. 
Table 2. The process changes the number of structural units with the different number of MD moving steps.

\begin{tabular}{cccccc}
\hline Atoms number (atoms) & $2 \times 10^{3}$ & $4 \times 10^{3}$ & $6 \times 10^{3}$ & $8 \times 10^{3}$ & $10 \times 10^{3}$ \\
\hline FCC & 12 & 19 & 18 & 37 & 43 \\
HCP & 60 & 112 & 162 & 219 & 265 \\
BCC & 6 & 11 & 16 & 24 & 28 \\
Amor & 1922 & 3858 & 5804 & 7720 & 9664 \\
\hline
\end{tabular}

increases from 12 FCC to 43 FCC, HCP increases from 60 HCP to $265 \mathrm{HCP}$, $\mathrm{BCC}$ increases from $6 \mathrm{BCC}$ to $28 \mathrm{BCC}$, finishes increasing the number of structural units of FCC, BCC, which is not significant, only HCP increases rapidly (Table 2). Consequently, when increasing the atoms number and the number of shift steps of MD leads to a rapid increase in shape and the number of structural units of FCC, and the plastic deformation energy of PE also varies greatly. The result of the PE modeling process is consistent with the result [77] [78] [79] [80] and coincide with the previous authors who used the Monte Carlo (MC) method [62] [63] [64] with a PE transition temperature is $103 \mathrm{~K}$ [75] [76]. Additionally, when increasing the number of the atoms leads to the angle among the atoms is a constant corresponding to $109.5^{\circ}$, the length of the link $\mathrm{r}$ increases from $\mathrm{r}=$ $1.529 \AA$ to $\mathrm{r}=1.558 \AA$, the obtained result is correctly consistent with the result of bonding angle of $109.27^{\circ}$, and the link length $r=1.529 \AA$ [62] [77], the size of the PE material increase from $l=3.73 \mathrm{~nm}$ to $l=6.63 \mathrm{~nm}$, the total energy $E_{\text {total }}$ decreases from $\mathrm{E}_{\text {total }}=-1586 \mathrm{eV}$ to $\mathrm{E}_{\text {total }}=-7891 \mathrm{eV}$. This means that when increasing the number the atoms leads to increase the link length, $\mathrm{E}_{\text {total }}$ decreases and changes the plastic deformation characteristics of PE.

\subsubsection{The Effect of Annealing Time}

Similarly, the effect of annealing time of PE material with $\mathrm{N}=10,000$ atoms at $\mathrm{T}$ $=100 \mathrm{~K}$, the results are shown in Figures 5-7.

The results show that with $t=50 \mathrm{ps}$, the shape (Figure $6(\mathrm{a})$ ), the number of structural units is $54 \mathrm{FCC}, 280 \mathrm{HCP}, 35 \mathrm{BCC}$ (Figure 7(a)), the plastic deformation characteristics of PE (Figure 5(a)). When increasing the annealing time from $t=50$ ps to $t=100$ ps, 150 ps, 200 ps lead to FCC, HCP, BCC decreases and Amor increases accordingly: with $t=50$ ps, there are 54 FCC, $280 \mathrm{HCP}, 35$ BCC, 9581 Amor; $\mathrm{t}=100$ ps has 43 FCC, 265 HCP, 28 BCC, 9564 Amor; $t=150$ ps has 51 FCC, 268 HCP, 23 BCC, 9508 Amor; $t=200$ ps has 42 FCC, 278 HCP, 19 BCC, 9461 Amor (Figures 7(b)-(d)), shape (Figures 6(b)-(d)), and the plastic deformation characteristics (Figures 5(b)-(d)). Also, $\mathrm{E}_{\text {tot }}$ increased (Figure $5(\mathrm{e})$ ), free volume change the number of atoms (Figure 5(f)). This showed that after the annealing time, then FCC, HCP, BCC decreased, Amor, increased after finishing which did not make a significant change in the structure. 


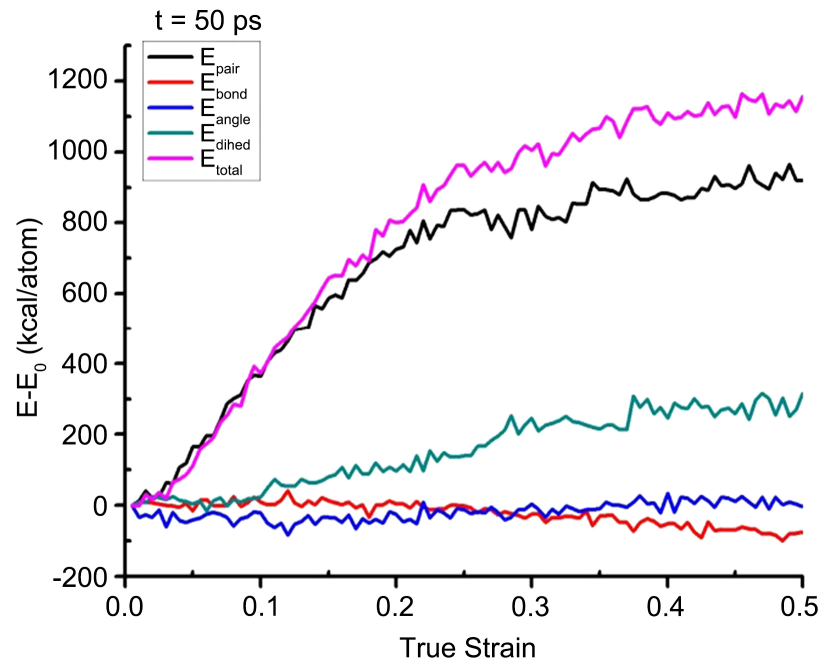

(a)

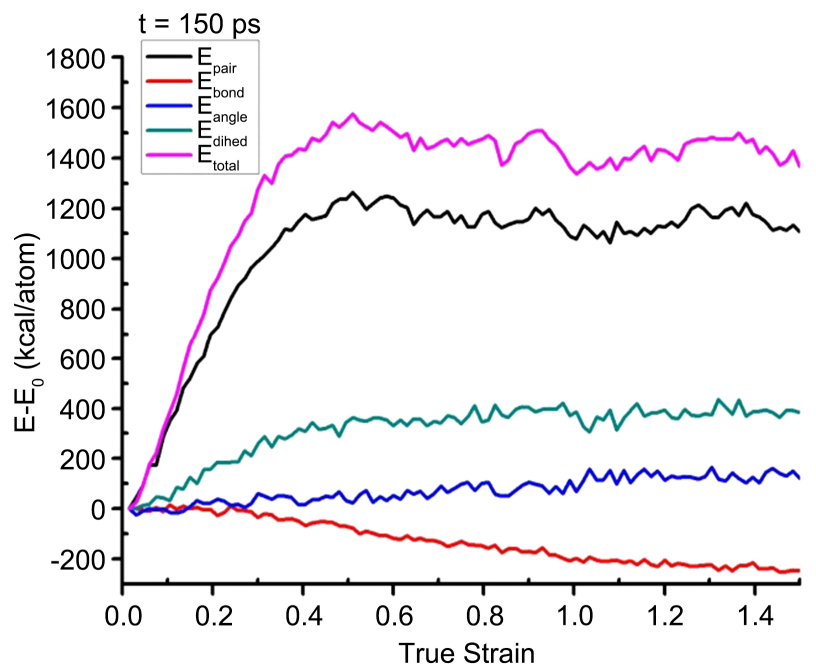

(c)

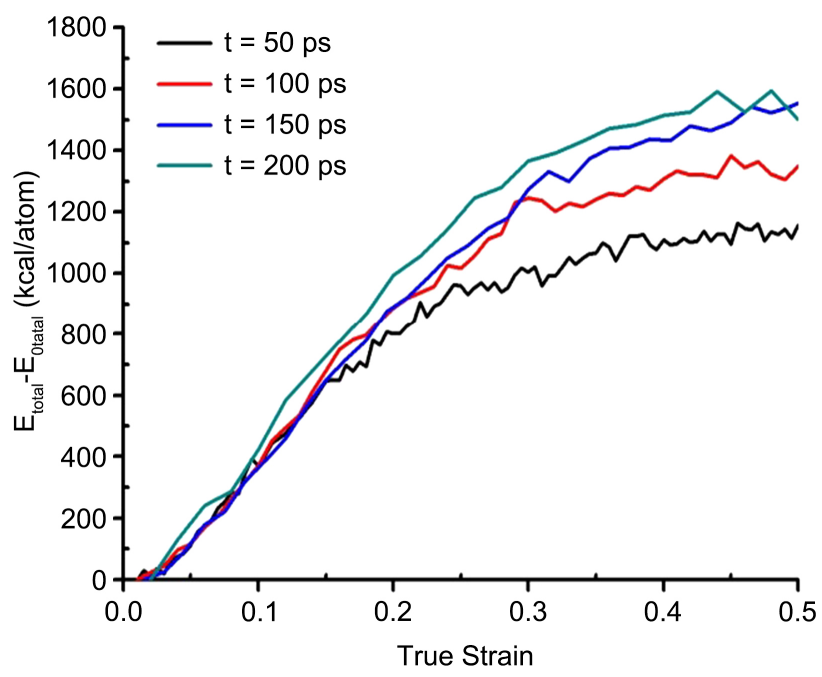

(e)

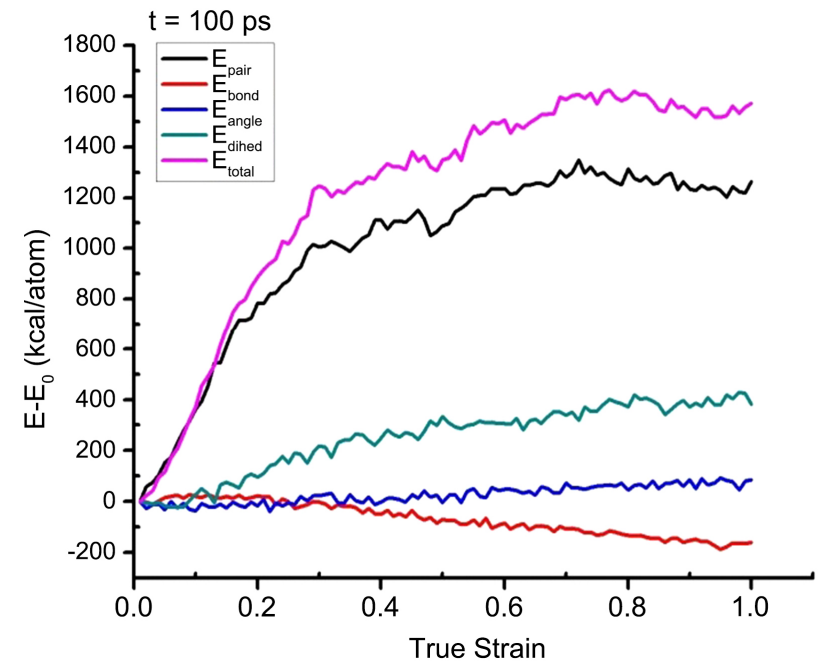

(b)

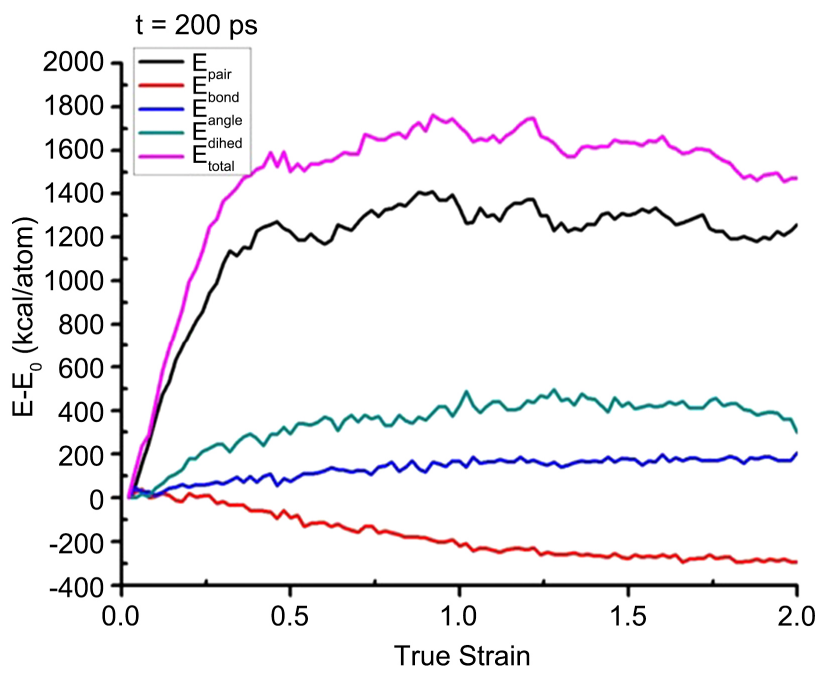

(d)

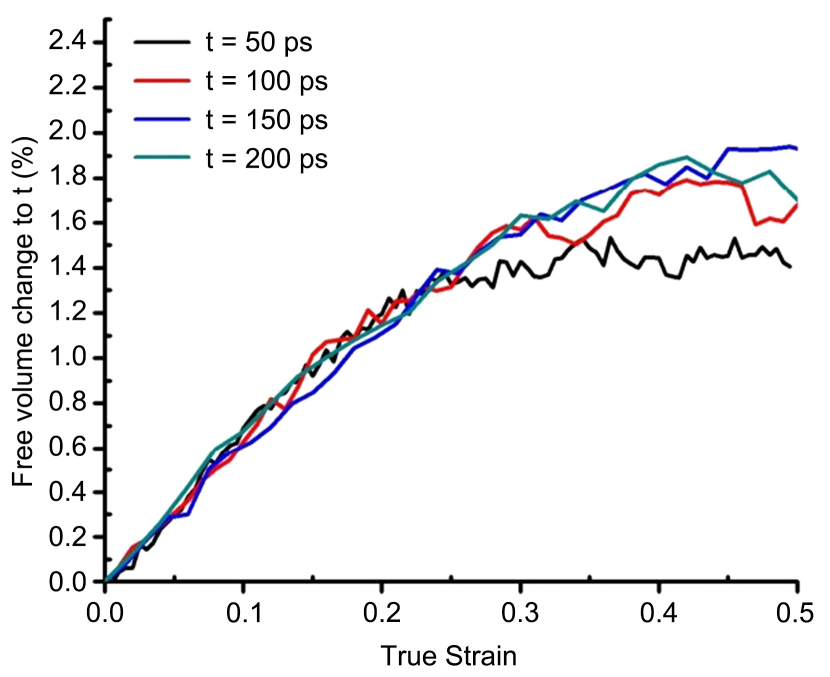

(f)

Figure 5. The plastic deformation process of $\mathrm{PE}$ at temperature $\mathrm{T}=100 \mathrm{~K}$ with $\mathrm{t}=50 \mathrm{ps}(\mathrm{a}), 100 \mathrm{ps}(\mathrm{b}), 150 \mathrm{ps}(\mathrm{c}), 200 \mathrm{ps}(\mathrm{d})$, total energy of system (e), free volume change number atoms (f). 


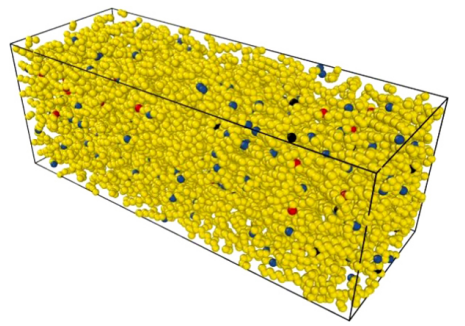

(a)

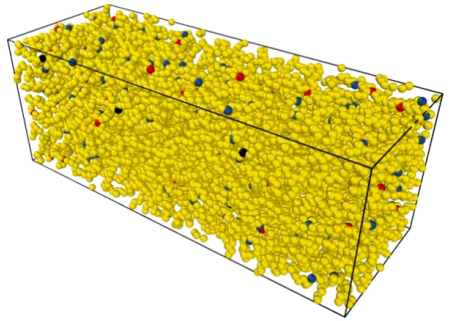

(c)

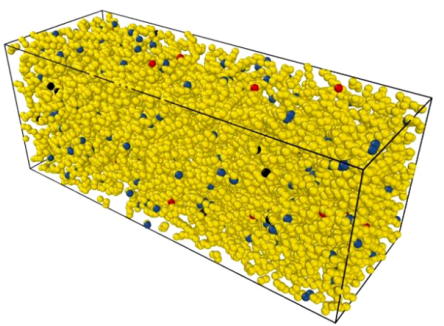

(b)

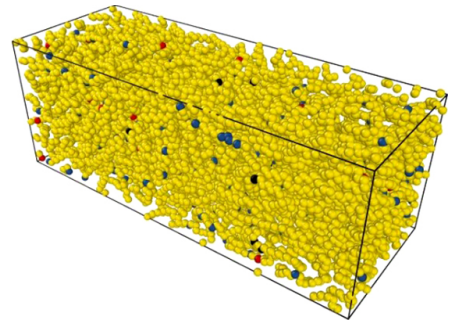

(d)

Figure 6. The shape of PE material after different annealing time as $t=50 \mathrm{ps}(\mathrm{a}), 100 \mathrm{ps}(\mathrm{b}), 150 \mathrm{ps}(\mathrm{c}), 200 \mathrm{ps}(\mathrm{d})$.

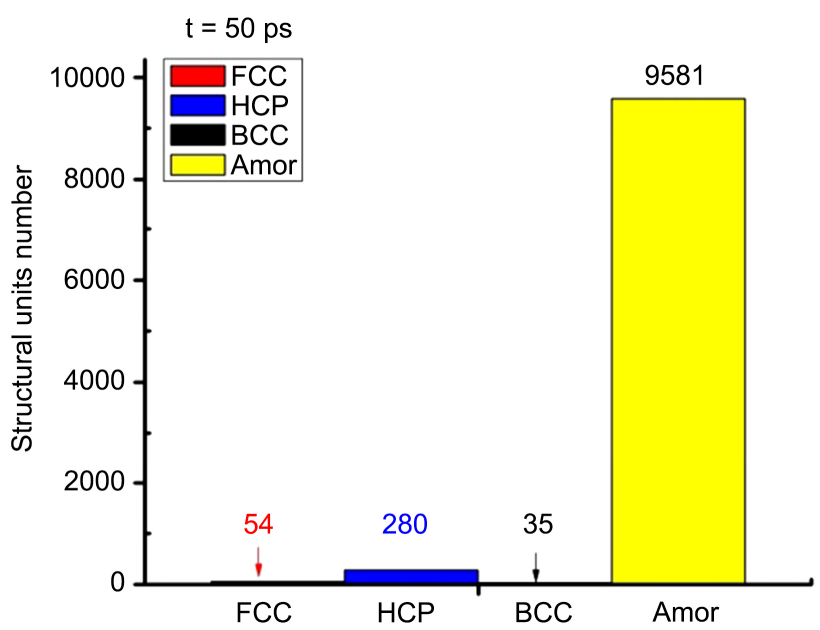

(a)

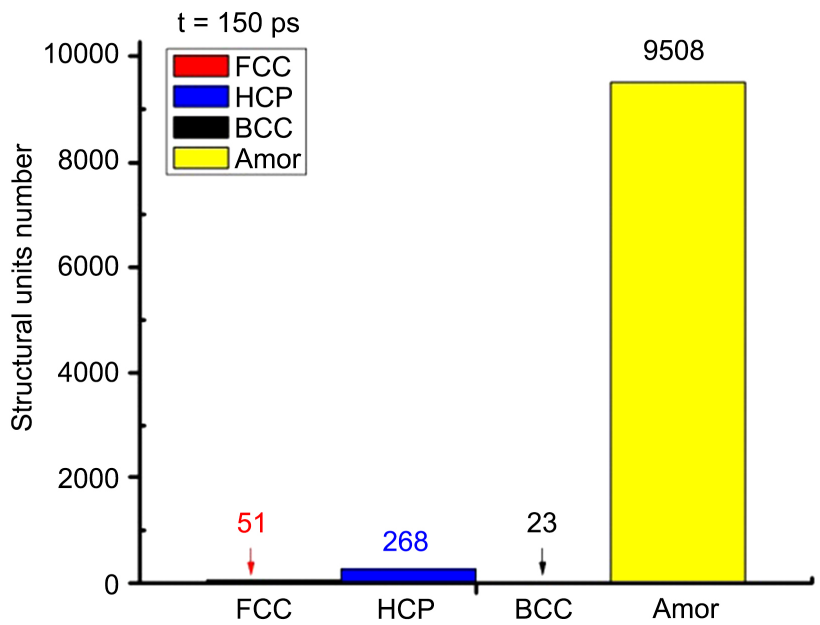

(c)

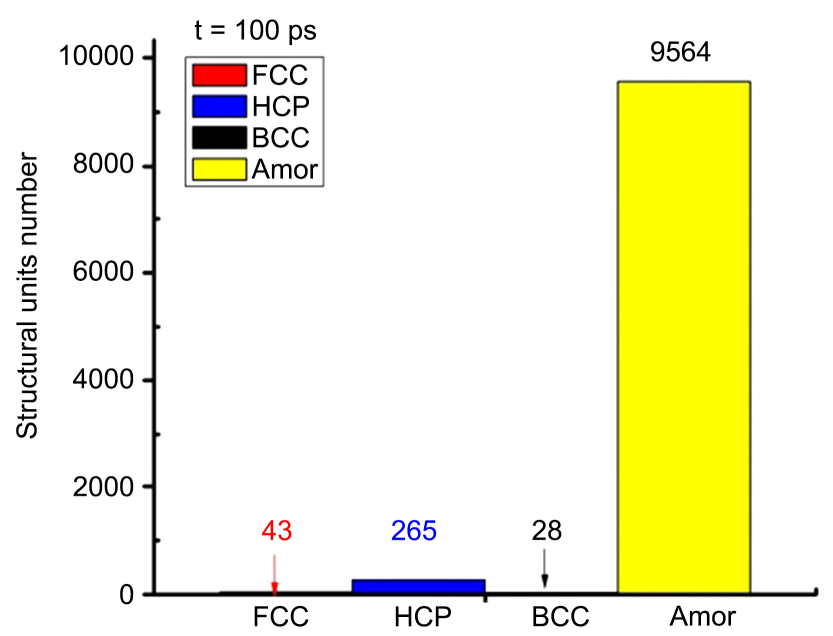

(b)

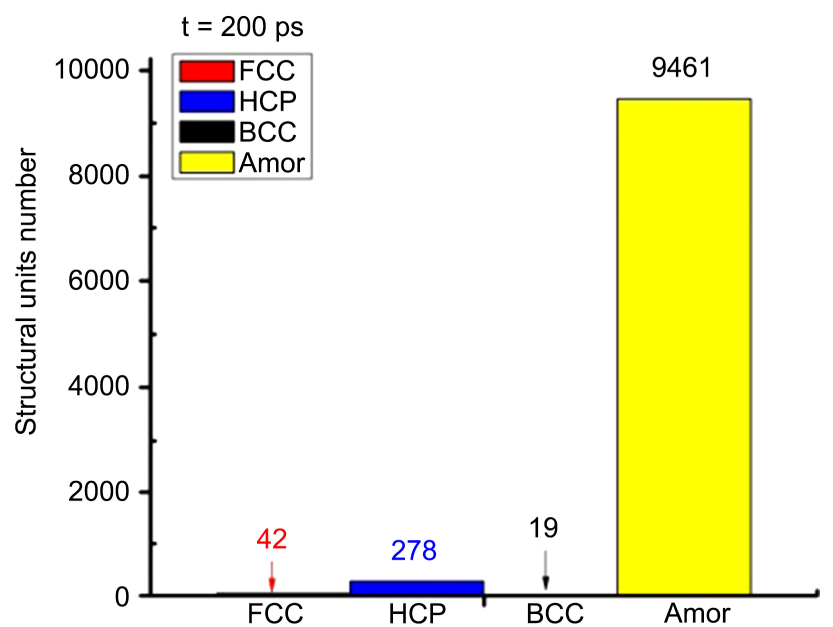

(d)

Figure 7. The number of structural units of FCC, HCP, BCC, Amor after the different annealing time: $t=50 \mathrm{ps}(\mathrm{a}), 100 \mathrm{ps}(\mathrm{b}), 150$ ps (c), 200 ps (d). 


\subsection{Influence of Temperature}

The result of the effect of $\mathrm{T}$ on the plastic deformation of PE 10,000 atoms, is shown in Figure 8, Figure 9.

The result shows that at the temperature $(\mathrm{T}), \mathrm{T}=40 \mathrm{~K}$ in which the number of structural units 47 FCC, 307 HCP, 18 BCC (Figure 9(a)) corresponding to the plastic deformation characteristics of $\mathrm{PE}$ (Figure 8). When increasing the temperature from $\mathrm{T}=40 \mathrm{~K}$ to $\mathrm{T}=60 \mathrm{~K}, 80 \mathrm{~K}, 100 \mathrm{~K}, 120 \mathrm{~K}$, then the number of structural units of FCC, HCP, BCC decreases, and Amor increases accordingly with $\mathrm{T}=40 \mathrm{~K}$, has $47 \mathrm{FCC}, 307 \mathrm{HCP}, 18 \mathrm{BCC}, 9628$ Amor; $\mathrm{T}=60 \mathrm{~K}$, which has 53 FCC, 267 HCP, 33 BCC, 9647 Amor; $\mathrm{T}=80 \mathrm{~K}$ has 56 FCC, $295 \mathrm{HCP}, 30 \mathrm{BCC}$, 9619 Amor; $\mathrm{T}=100 \mathrm{~K}$ has $43 \mathrm{FCC}, 265 \mathrm{HCP}, 28 \mathrm{BCC}, 9664$ Amor; $\mathrm{T}=120 \mathrm{~K}$ has 39 FCC, 303 HCP, 18 BCC, 9640 Amor (Figures 9(b)-(e)), the shape and plastic deformation characteristics of PE (Figures 8(a)-(f)). In addition, the $\mathrm{E}_{\text {tot }}$ increases (Figure 5(e)), which shows that when increasing temperature leads to the plastic deformation increases, and the structure is unchangeable. The obtained result shows that when increasing $\mathrm{N}$ leads to 1 increasing, $\mathrm{E}_{\text {tot }}$ decreases, and the number of structural units increases. When increasing the time of elongation and temperature, 1 increases, $E_{\text {tot }}$ increases, and the number of structural units of the system decrease. This result is the basis for future empirical research.

\section{Conclusion}

After studying the effect of the atomic number $(\mathrm{N})$, temperature $(\mathrm{T})$, and annealing time $(\mathrm{t})$ on the structure and the plastic deformation of the polyethylene, the result shows that when increasing $\mathrm{N}$, from $\mathrm{N}=2000$ atoms to $\mathrm{N}=10,000$ atoms, the moving number of MD leads to the shape and the number of structure units FCC increase. The angle among the atoms is a constant corresponding to $109.5^{\circ}$. The length of the link $r$ increases from $r=1.529 \AA$ to $r=1.558 \AA$. The plastic deformation energy of $\mathrm{PE}$ has an enormous change as the bonding angle of $109.27^{\circ}$. The length of the link $\mathrm{r}=1.529 \AA$, and the size of the PE material increases from $\mathrm{l}=3.73 \mathrm{~nm}$ to $\mathrm{l}=6.63 \mathrm{~nm}$. The total energy $\left(\mathrm{E}_{\text {total }}\right)$ decreases from $\mathrm{E}_{\text {total }}=-1586 \mathrm{eV}$ to $\mathrm{E}_{\text {total }}=-7891 \mathrm{eV}$, and it coincides with the previous authors who used the Monte Carlo (MC) method with a PE transition temperature is 103 $\mathrm{K}$. When $\mathrm{N}$ increasing leads to the length of the link increases, $\mathrm{E}_{\text {total }}$ decreases, FCC, HCP, BCC, Amor increases, and changes the plastic deformation characteristics of $\mathrm{PE}$ with an increase in $\mathrm{T}$ and the $\mathrm{t}$. The obtained results are very significant for future experimental research as studying the effect of the number of structural units on the structure, plastic deformation, conductivity, magnetism of PE materials.

\section{Acknowledgements}

We thank computer room, Faculty of Physics of Hanoi National University of Education has created all favorable conditions, help us throughout the process of calculating, simulating and finishing the content of the article. 


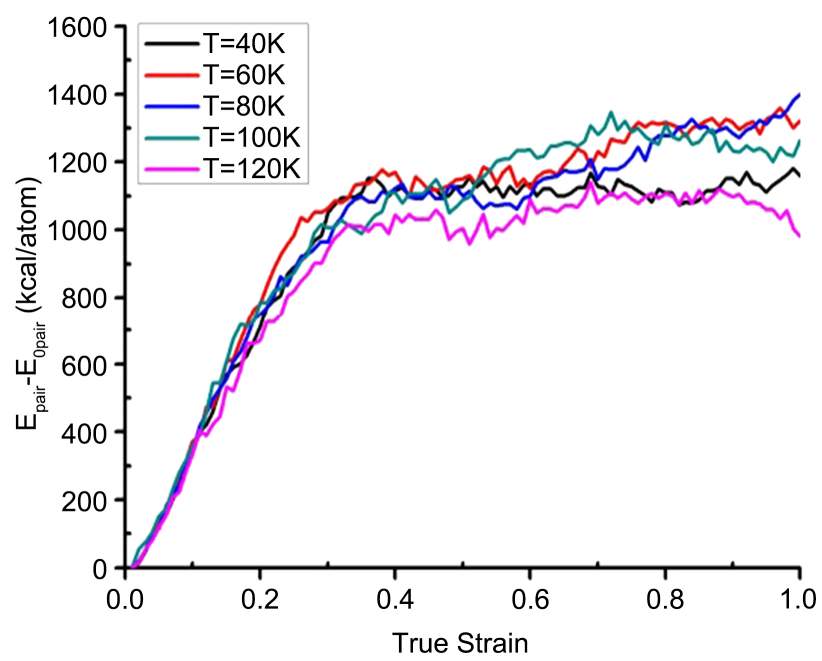

(a)

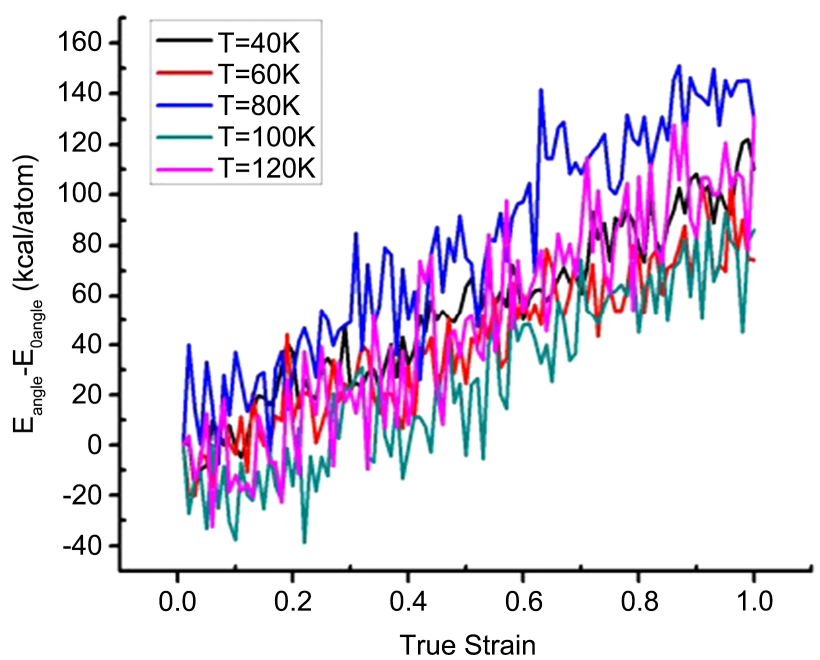

(c)

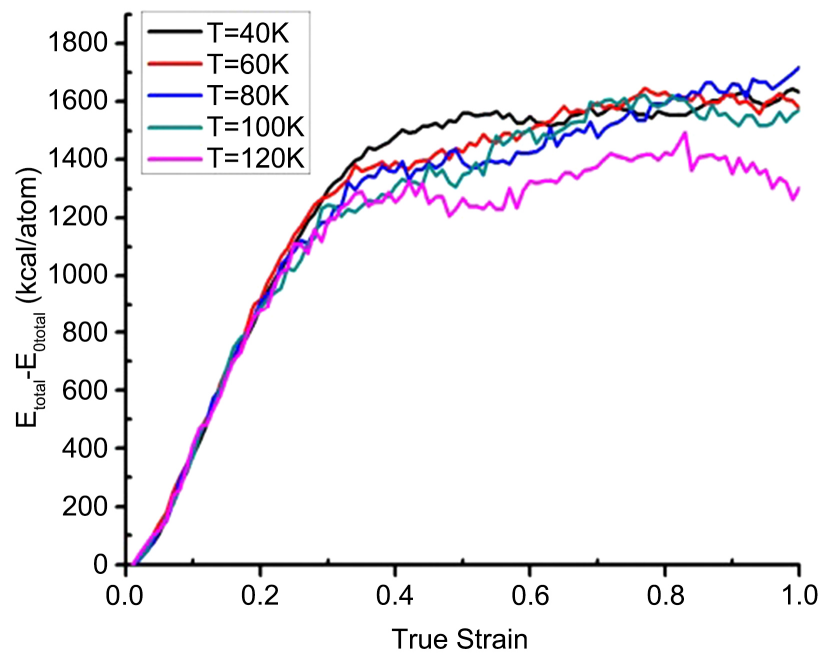

(e)

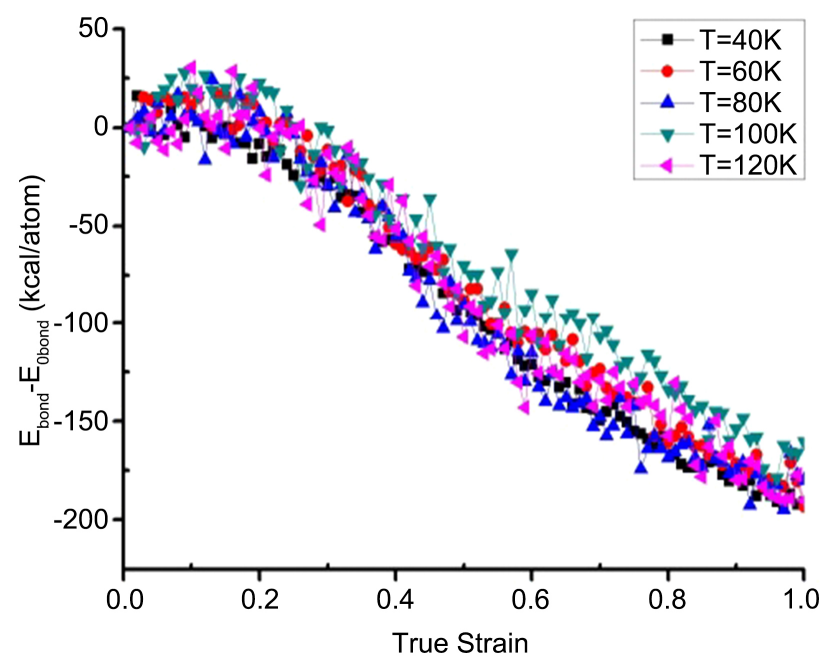

(b)

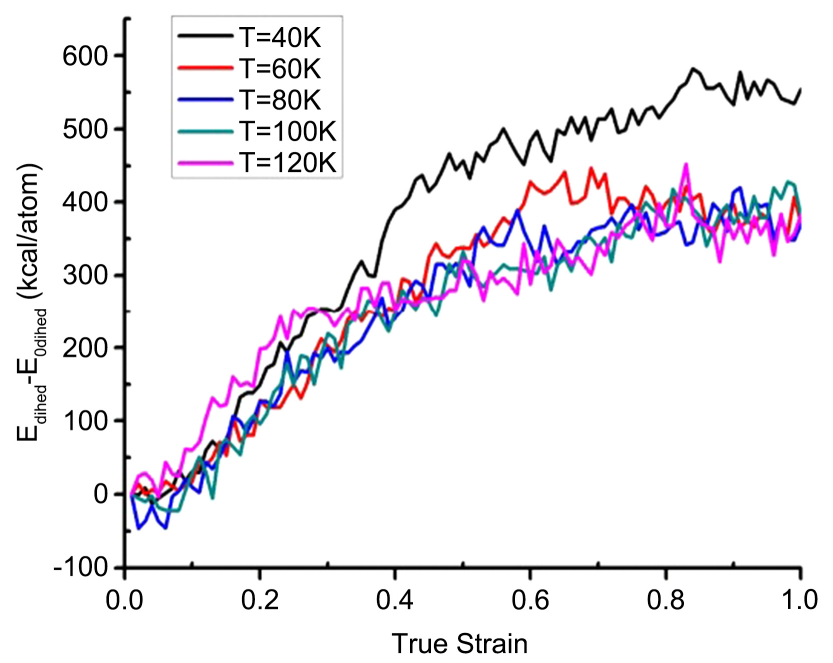

(d)

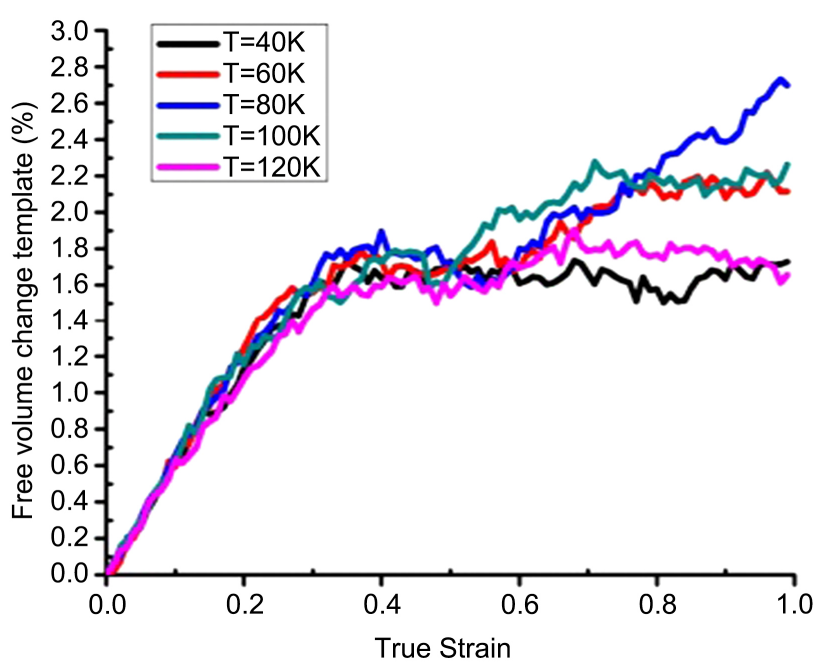

(f)

Figure 8. The plastic deformation process of PE 10,000 atoms with the total energy pair $\mathrm{E}_{\text {pair }}(\mathrm{a})$, the total electron bond energy $E_{\text {bond }}(b)$, the total energy angle $E_{\text {angle }}(c)$, the total dihedral energy $E_{\text {dihed }}(d)$, the total energy $E_{\text {tot }}(e)$, the free volume change the number of atoms (f) at the temperature $\mathrm{T}=100 \mathrm{~K}$ with different temperatures. 


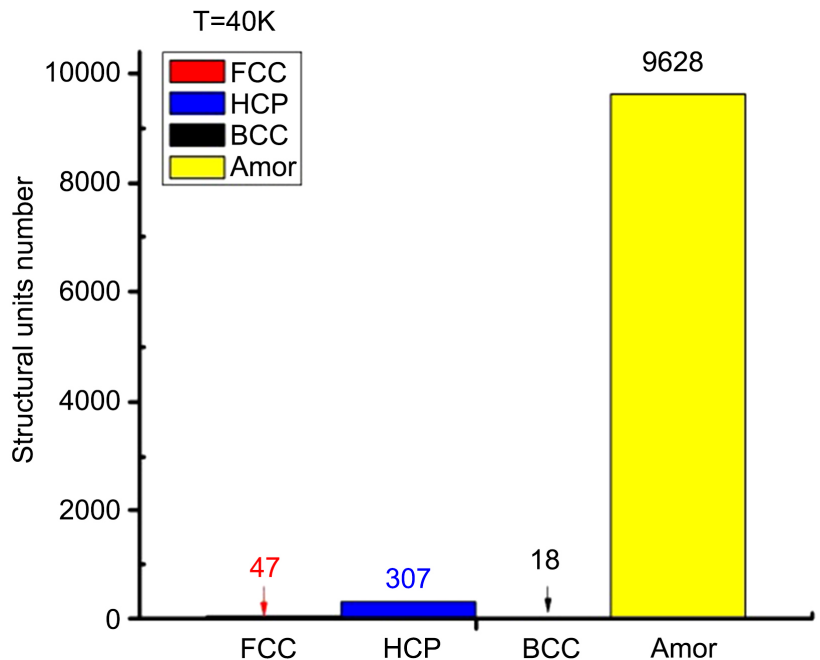

(a)

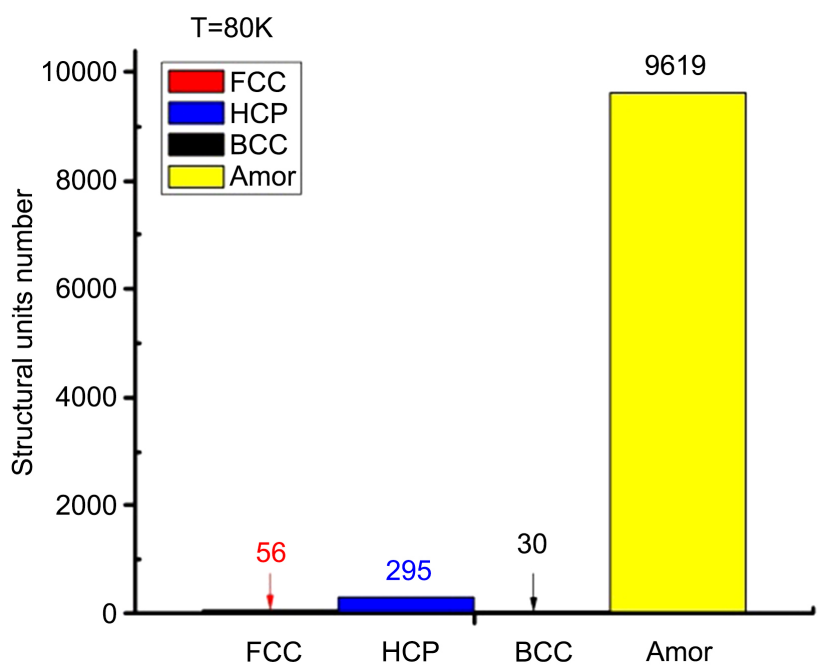

(c)

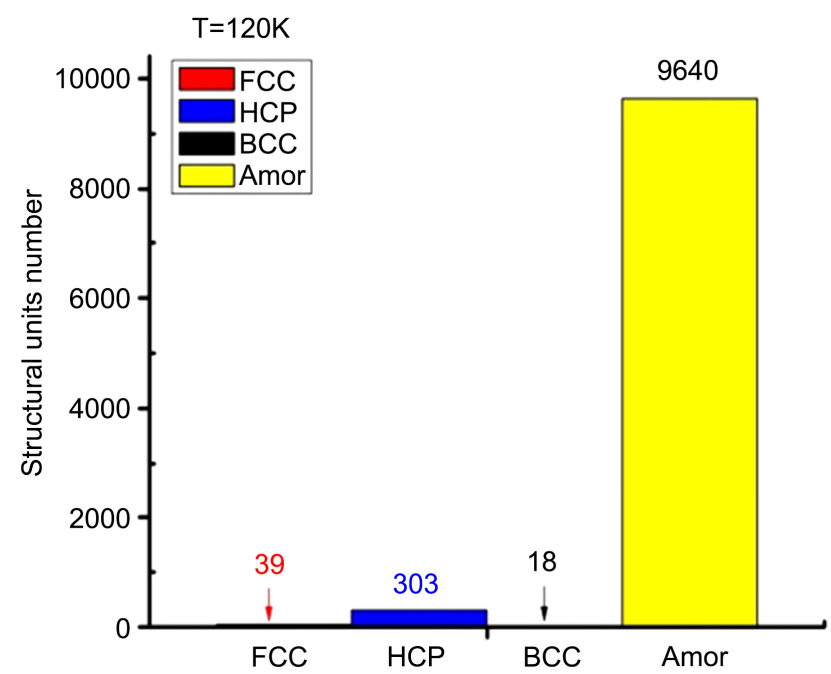

(e)

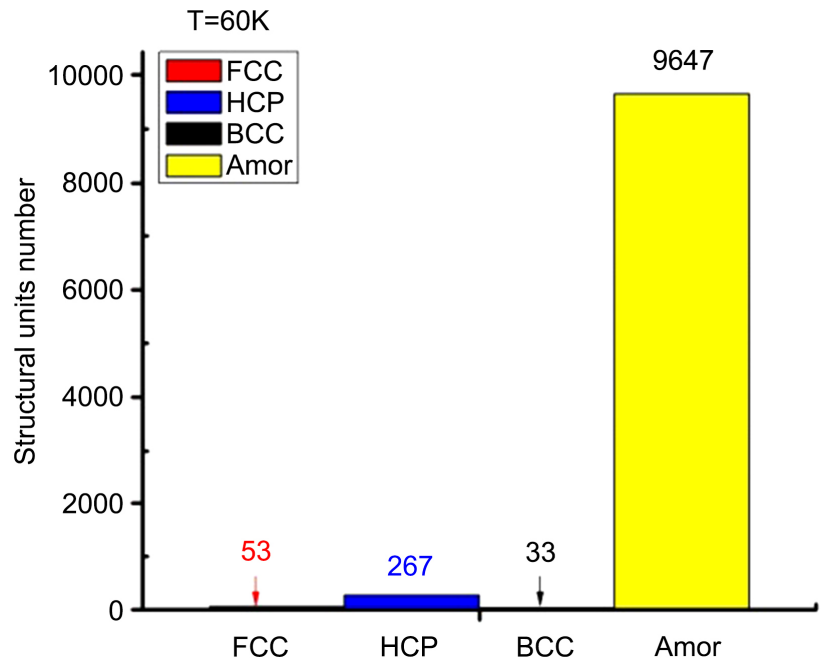

(b)

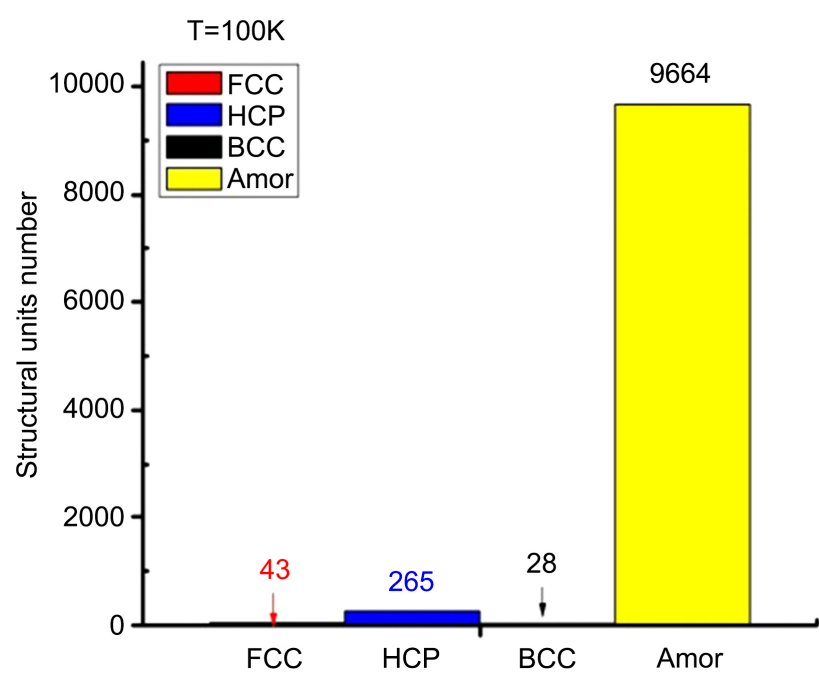

(d) 


\section{Conflicts of Interest}

The authors declare no conflicts of interest regarding the publication of this paper.

\section{References}

[1] Eyring, H. (1936) Viscosity, Plasticity, and Diffusion as Examples of Absolute Reaction Rates. The Journal of Chemical Physics, 4, 283. https://doi.org/10.1063/1.1749836

[2] Robertson, R. (1966) Theory for the Plasticity of Glassy Polymers. The Journal of Chemical Physics, 44, 3950. https://doi.org/10.1063/1.1726558

[3] Youngquist, J., Myers, G.E., Ageney, U. and Luther, W.M. (1992) Lignocellulosic-Plastic Composites from Recycled Materials. Forest, 2, 1-2. https://doi.org/10.1021/bk-1992-0476.ch004

[4] Bledzki, A.K., Gassan, J. and Theis, S. (1998) Wood-Filled Thermoplastic Composites. Mechanics of Composite Materials, 34, 563-568. https://doi.org/10.1007/BF02254666

[5] Sewda, K. and Maiti, S.N. (2013) Dynamic Mechanical Properties of High Density Polyethylene and Teak Wood Flour Composites. Polymer Bulletin, 70, 2657-2674. https://doi.org/10.1007/s00289-013-0941-0

[6] Selke, S.E. and Wichman, I. (2004) Wood Fiber/Polyolefin Composites. Composite Part A, 35, 321-326. https://doi.org/10.1016/j.compositesa.2003.09.010

[7] Joshi, S.V., Drzal, L.T., Mohanty, A.K. and Arora, S. (2004) Are Natural Fiber Composites Environmentally Superior to Glass Fiber Reinforced Composites? Composite Part A, 35, 371-376. https://doi.org/10.1016/j.compositesa.2003.09.016

[8] Orhan, Y. and Büyükgüngör, H. (2000) Enhancement of Biodegradability of Disposable Polyethylene in Controlled Biological Soil. International Biodeterioration \& Biodegradation, 45, 49-55. https://doi.org/10.1016/S0964-8305(00)00048-2

[9] Bledzki, A.K. and Gassan, J. (1999) Composites Reinforced with Cellulose Based Fibres. Progress in Polymer Science, 24, 221-274. https://doi.org/10.1016/S0079-6700(98)00018-5

[10] Maiti, S.N. and Hassan, M.R. (1989) Melt Rheological Properties of Polypropylene-Wood Flour Composites. Journal of Applied Polymer Science, 37, 2019-2032. https://doi.org/10.1002/app.1989.070370721

[11] Li, Q. and Matuana, L.M. (2003) Surface of Cellulosic Materials Modified with Functionalized Polyethylene Coupling Agents. Journal of Applied Polymer Science, 88, 278-286. https://doi.org/10.1002/app.11681

[12] Rizvi, G., Matuana, L.M. and Park, C.B. (2000) Foaming of PS/Wood Fiber Composites Using Moisture as a Blowing Agent. Polymer Engineering \& Science, 40, 2124-2132. https://doi.org/10.1002/pen.11345

[13] Patil, Y.P., Gajre, B., Dusane, D., Chavan, S. and Mishra, S. (2000) Effect of Maleic Anhydride Treatment on Steam and Water Absorption of Wood Polymer Composites Prepared from Wheat Straw, Cane Bagasse, and Teak Wood Sawdust Using Novolac as Matrix. Journal of Applied Polymer Science, 77, 2963-2967. https://doi.org/10.1002/1097-4628(20000923)77:13<2963::AID-APP20>3.0.CO;2-0

[14] Rowell, R.M., Sanadi, A.R., Caulfield, D.F., Jacobson, E., Leo, A.L., Carvalho, F.X. and Frollini, E. (1997) Utilization of Natural Fibers in Plastic Composites: Problems and Opportunities. Forest, 2, 23-51. 
[15] Zhang, M.Q., Rong, M.Z. and Lu, X. (2005) Fully Biodegradable Natural Fiber Composites from Renewable Resources: All-Plant Fiber Composite. Composites Science and Technology, 65, 2514-2525. https://doi.org/10.1016/j.compscitech.2005.06.018

[16] Saheb, D.N. and Jog, J.P. (1999) Natural Fiber Polymer Composites: A Review. Polymers for Advanced Technologies, 18, 351-363. https://doi.org/10.1002/(SICI)1098-2329(199924)18:4<351::AID-ADV6>3.0.CO;2-X

[17] Balasuriya, P.W., Ye, L. and Mai, Y.W. (2001) Mechanical Properties of Wood Flake-Polyethylene Composites. Part I: Effects of Processing Methods and Matrix Melt Flow Behaviour. Compos A, 32, 619-629. https://doi.org/10.1016/S1359-835X(00)00160-3

[18] Brydson, J.A. (1999) Plastics Materials. Butterworth Heinemann, New York.

[19] Stark, N.M. and Matuana, L.M. (2003) Ultraviolet Weathering of Photostabilized Wood-Flour Filled High-Density Polyethylene Composites. Journal of Applied Polymer Science, 90, 2609-2617. https://doi.org/10.1002/app.12886

[20] Stark, N.M. and Matuana, L.M. (2004) Surface Chemistry Changes of Weathered HDPE/Wood-Flour Composites Studied by XPS and FTIR Spectroscopy. Polymer Degradation and Stability, 86, 1-9. https://doi.org/10.1016/j.polymdegradstab.2003.11.002

[21] Van Krevelen, D.W. (1990) Properties of Polymers. 3rd Edition, Elsevier, Amsterdam.

[22] Kim, D.-M. and Iedema, P.D. (2004) Molecular Weight Distribution in Low-Density Polyethylene Polymerization; Impact of Scission Mechanisms in the Case of a Tubular Reactor. Chemical Engineering Science, 59, 2039-2052. https://doi.org/10.1016/j.ces.2004.02.002

[23] Verros, G.D. (2003) Calculation of Molecular Weight Distribution in Non-Linear Free Radical Copolymerization. Polymer, 44, 7021-7032. https://doi.org/10.1016/j.polymer.2003.08.029

[24] Pladis, P. and Kiparissides, C. (1998) A Comprehensive Model for the Calculation of Molecular Weight + Long-Chain Branching Distribution in Free-Radical Polymerizations. Chemical Engineering Science, 53, 3315-3333. https://doi.org/10.1016/S0009-2509(98)00133-X

[25] Cervantes, A.M., Tonelli, S., Brandolin, A., Bandoni, J.A. and Biegler, L.T. (2002) Large-Scale Dynamic Optimization for Grade Transitions in a Low Density Polyethylene Plant. Computers \& Chemical Engineering, 26, 227-237. https://doi.org/10.1016/S0098-1354(01)00743-8

[26] Sun, L.Y., Gibson, R.F., Gordaninejad, F. and Suhr, J. (2009) Energy Absorption Capability of Nanocomposites: A Review. Composites Science and Technology, 69, 2392-2409. https://doi.org/10.1016/j.compscitech.2009.06.020

[27] McShane, G.J., Stewart, C., Aronson, M.T., Wadley, H.N.G., Fleck, N.A. and Deshpande, V.S. (2008) Dynamic Rupture of Polymer-Metal Bilayer Plates. International Journal of Solids and Structures, 45, 4407-4426. https://doi.org/10.1016/j.ijsolstr.2008.03.017

[28] Amini, M.R., Simon, J. and Nemat-Nasser, S. (2010) Numerical Modeling of Effect of Polyurea on Response of Steel Plates to Impulsive Loads in Direct Pressure-Pulse Experiments. Mechanics of Materials, 42, 615-627. https://doi.org/10.1016/j.mechmat.2009.09.009

[29] Jatin, Sudarkodi, V. and Basu, S. (2014) Investigations into the Origins of Plastic Flow and Strain Hardening in Amorphous Glassy Polymers. International Journal 
of Plasticity, 56, 139-155. https://doi.org/10.1016/j.ijplas.2013.11.007

[30] Kurtz, S.M., Rimnac, C.M., Santner, T.J. and Bartel, D.L. (1996) Exponential Model for the Tensile True Stress-Strain Behavior of As-Irradiated and Oxidatively Degraded Ultra-High Molecular Weight Polyethylene. Journal of Orthopaedic Research, 14, 755-761. https://doi.org/10.1002/jor.1100140512

[31] Pouriayevali, H., Arabnejad, S., Guo, Y.B. and Shim, V.P.W. (2013) A Constitutive Description of the Rate-Sensitive Response of Semi-Crystalline Polymers. International Journal of Impact Engineering, 62, 35-47. https://doi.org/10.1016/j.ijimpeng.2013.05.002

[32] Epee, A.F., Lauro, F., Bennani, B. and Bourel, B. (2011) Constitutive Model for a Semi-Crystalline Polymer under Dynamic Loading. International Journal of Solids and Structures, 48, 1590-1599. https://doi.org/10.1016/j.ijsolstr.2011.02.009

[33] Argon, A.S. (1973) A Theory for the Low-Temperature Plastic Deformation of Glassy Polymers. Philosophical Magazine, 28, 839. https://doi.org/10.1080/14786437308220987

[34] Baschnagel, J., Binder, K., Doruker, P., Gusev, A.A., Hahn, O., Kremer, K., et al. (2000) Bridging the Gap between Atomistic and Coarse-Grained Models of Polymers: Status and Perspectives. In: Viscoelasticity, Atomistic Models, Statistical Chemistry, Vol. 152, Springer, Berlin, 41-156. https://doi.org/10.1007/3-540-46778-5_2

[35] Paul, W., Yoon, D.Y. Smith, G.D. (1995) An Optimized United Atom Model for Simulations of Polymethylene Melts. The Journal of Chemical Physics, 103, 1702-1709. https://doi.org/10.1063/1.469740

[36] Yoon, D.Y., Smith, G.D. and Matsuda, T. (1993) A Comparison of a United Atom and an Explicit Atom Model in Simulations of Polymethylene. The Journal of Chemical Physics, 98, 10037-10043. https://doi.org/10.1063/1.464436

[37] Faller, R. and Muller-Plathe, F. (2002) Modeling of Poly (Isoprene) Melts on Different Scales. Polymer, 43, 621-628. https://doi.org/10.1016/S1089-3156(01)00013-7

[38] Fukunaga, H., Takimoto, J. and Doi, M. (2002) A Coarse-Graining Procedure for Flexible Polymer Chains with Bonded and Nonbonded Interactions. The Journal of Chemical Physics, 116, 8183-8190. https://doi.org/10.1063/1.1469609

[39] Müller-Plathe, F. (2002) Coarse-Graining in Polymer Simulation: From the Atomistic to the Mesoscopic Scale and Back. ChemPhysChem, 3, 754-769. https://doi.org/10.1002/1439-7641(20020916)3:9<754::AID-CPHC754>3.0.CO;2-U

[40] Uhlherr, A. and Theodorou, D.N. (1998) Hierarchical Simulation Approach to Structure and Dynamics of Polymers. Current Opinion in Solid State \& Materials Science, 3, 544-551. https://doi.org/10.1016/S1359-0286(98)80023-5

[41] Deng, D., Argon, A.S. and Yip, S. (1989) Simulation of Plastic Deformation in a Two-Dimensional Atomic Glass by Molecular Dynamics IV. Philosophical Transactions of the Royal Society of London, 329, 613. https://doi.org/10.1098/rsta.1989.0092

[42] Maeda, K. and Takeuchi, S. (1981) Atomistic Process of Plastic Deformation in a Model Amorphous Metal. Philosophical Magazine A, 44, 643-656. https://doi.org/10.1080/01418618108236167

[43] Srolovitz, D., Vitek, V. and Egami, T. (1983) An Atomistic Study of Deformation of Amorphous Metals. Acta Metallurgica et Materialia, 31, 335-352. https://doi.org/10.1016/0001-6160(83)90110-4

[44] Theodorou, D. and Suter, U. (1985) Detailed Molecular Structure of a Vinyl Polymer Glass. Macromolecules, 18, 1467. https://doi.org/10.1021/ma00149a018 
[45] Theodorou, D. and Suter, U. (1986) Atomistic Modeling of Mechanical Properties of Polymeric Glasses. Macromolecules, 19, 139. https://doi.org/10.1021/ma00155a022

[46] Mott, P., Argon, A.S. and Suter, U. (1993) Atomistic Modelling of Plastic Deformation of Glassy Polymers. Philosophical Magazine, 67, 931. https://doi.org/10.1080/01418619308213969

[47] Hutnik, M., Argon, A.S. and Suter, U. (1993) Simulation of Elastic and Plastic Response in the Glassy Polycarbonate of 4,4'-Isopropylidenediphenol. Macromolecules, 26, 1097. https://doi.org/10.1021/ma00057a034

[48] Brown, D. and Clarke, J. (1991) Molecular Dynamics Simulation of an Amorphous Polymer under Tension. 1. Phenomenology. Macromolecules, 24, 2075. https://doi.org/10.1021/ma00008a056

[49] Kremer, K. (2001) Multiscale Problems in Polymer Science: Simulation Approaches. MRS Bulletin, 26, 205-210. https://doi.org/10.1557/mrs2001.43

[50] Depa, P.K. and Maranas, J.K. (2005) Speed Up of Dynamic Observables in CoarseGrained Molecular-Dynamics Simulations of Unentangled Polymers. The Journal of Chemical Physics, 123, Article ID: 094901. https://doi.org/10.1063/1.1997150

[51] Depa, P.K. and Maranas, J.K. (2007) Dynamic Evolution in Coarse-Grained Molecular Dynamics Simulations of Polyethylene Melts. The Journal of Chemical Physics, 126, Article ID: 054903. https://doi.org/10.1063/1.2433724

[52] Lavine, M.S., Waheed, N. and Rutledge, G.C. (2003) Molecular Dynamics Simulation of Orientation and Crystallization of Polyethylene during Uniaxial Extension. Polymer, 44, 1771-1779. https://doi.org/10.1016/S0032-3861(03)00017-X

[53] Pearson, D.S., Ver Strate, G., Von Meerwall, E. and Schilling, F.C. (1987) Viscosity and Self-Diffusion Coefficient of Linear Polyethylene. Macromolecules, 20, 1133-1141. https://doi.org/10.1021/ma00171a044

[54] Tries, V., Paul, W., Baschnagel, J. and Binder, K. (1997) Modeling Polyethylene with the Bond Fluctuation Model. The Journal of Chemical Physics, 106, 738-748.

https://doi.org/10.1063/1.473162

[55] Capaldi, F.M., Boyce, M.C. and Rutledge, G.C. (2001) Enhanced Mobility Accompanies the Active Deformation of a Glassy Amorphous Polymer. Physical Review Letters, 89, Article ID: 175505.

[56] Yang, L., Srolovitz, D.J. and Yee, A.F. (1999) Molecular Dynamics Study of Isobaric and Isochoric Glass Transitions in a Model Amorphous Polymer. The Journal of Chemical Physics, 110, 7058-7069. https://doi.org/10.1063/1.478611

[57] Takeuchi, H. and Roe, R.J. (1991) Molecular Dynamics Simulation of Local Chain Motion in Bulk Amorphous Polymers. II. Dynamics at Glass Transition. The Journal of Chemical Physics, 94, 7458-7465. https://doi.org/10.1063/1.460176

[58] Baltsas, A., Papadopoulos, E. and Kiparissides, C. (1998) Application and Validation of the Pseudo-Kinetic Rate Constant Method to High Pressure LDPE Tubular Reactors. Computers \& Chemical Engineering, 22, S95-S102.

https://doi.org/10.1016/S0098-1354(98)00042-8

[59] Haefele, M., Kienle, A., Boll, M. and Schmidt, C.-U. (2006) Modeling and Analysis of a Plant for the Production of Low Density Polyethylene. Computers \& Chemical Engineering, 31, 51-65. https://doi.org/10.1016/j.compchemeng.2006.05.001

[60] Asteasuain, M., Tonelli, S.M., Brandolin, A. and Bandoni, J.A. (2001) Dynamic Simulation and Optimisation of Tubular Polymerisation Reactors in gPROMS. Computers \& Chemical Engineering, 25, 509-515. 
https://doi.org/10.1016/S0098-1354(01)00631-7

[61] Bezzo, F., Macchietto, S. and Pantelides, C.C. (2000) A General Framework for the Integration of Computational Fluid Dynamics and Process Simulation. Computers \& Chemical Engineering, 24, 653-658. https://doi.org/10.1016/S0098-1354(00)00372-0

[62] Li, J., Mulder, T., Vorselaars, B., Lyulin Alexey, V. and Michels, M.A. (2006) Monte Carlo Simulation of Uniaxial Tension of an Amorphous Polyethylene-Like Polymer Glass. Macromolecules, 39, 7774-7782. https://doi.org/10.1021/ma061042w

[63] Li, J., Mulder, T., Vorselaars, B., Lyulin, A.V. and Michels, M.A.J. (2006) Monte Carlo Simulation of Uniaxial Tension of an Amorphous Polyethylene-Like Polymer Glass. Macromolecules, 39, 7774-7782. https://doi.org/10.1021/ma061042w

[64] Ospina, S.A., Restrepo, J. and Lopez, B.L. (2003) Deformation of Polyethylene: Monte Carlo Simulation. Materials Research Innovations, 7, 27-30. https://doi.org/10.1080/14328917.2003.11784755

[65] Brostow, W. and Corneliussen, R.D. (1986) Failure of Plastics. Hanser, New York.

[66] David, D.J. and Mishra, A. (1999) Relating Materials Properties to Structure: Handbook and Software for Polymer Calculations and Material Properties. Technomic Publishing Co., Lancaster.

[67] Boyd, R.H. (1985) Relaxation Processes in Crystalline Polymers: Molecular Interpretation-A Review. Polymer, 26, 1123-1133. https://doi.org/10.1016/0032-3861(85)90240-X

[68] Murayama, T. (1987) Polymers: An Encyclopedic Source Book of Engineering Properties Encyclopedia Reprint Series. John Wiley \& Sons, New York.

[69] Khonakdar, H.A., Morshedian, J., Wagenknecht, U. and Jafari, S.H. (2003) An Investigation of Chemical Crosslinking Effect on Properties of High Density Polyethylene. Polymer, 44, 4301-4309. https://doi.org/10.1016/S0032-3861(03)00363-X

[70] Munaro, M. and Akcelrud, L. (2008) Correlations between Composition and Crystallinity of LDPE/HDPE Blends. Journal of Polymer Research, 15, 83-88. https://doi.org/10.1007/s10965-007-9146-2

[71] Sha, H., Zhang, X. and Harrison, I.R. (1991) A Dynamic Mechanical Thermal Analysis (DMTA) Study of Polyethylenes. Thermochimica Acta, 192, 233-242. https://doi.org/10.1016/0040-6031(91)87165-S

[72] Sirotkin, R.O. and Brooks, N.W. (2001) The Dynamic Mechanical Relaxation Behaviour of Polyethylene Copolymers Cast from Solution. Polymer, 42, 9801. https://doi.org/10.1016/S0032-3861(01)00535-3

[73] Goertzen, W.K. and Kessler, M.R. (2007) Dynamic Mechanical Analysis of Carbon/Epoxy Composites for Structural Pipeline Repair. Composites Part B: Engineering, 38, 1-9. https://doi.org/10.1016/j.compositesb.2006.06.002

[74] Kroschwitz, J.I. (1990) Concise Encyclopedia of Polymer Science and Technology. John Wiley and Sons, New York.

[75] Lin, Z., Lin, Z., Zhen, S., Kui, N., Ami, M.I., Ayw, Y.W. and Xei, H.K. (1995) Electrical insulating materials. International Symposium on Electrical Insulating Materials, Tokyo, 17-20 September 1995, 173-176.

[76] Boyer, R.F. (1968) Dependence of Mechanical Properties on Molecular Motion in Polymers. Polymer Engineering \& Science, 8, 161-185. https://doi.org/10.1002/pen.760080302

[77] Bartczak, Z., Argon, A.S. and Cohen, R.E. (1992) Deformation Mechanisms and Plastic Resistance in Single-Crystal-Textured High-Density Polyethylene. Macro- 
molecules, 25, 5036-5053 https://doi.org/10.1021/ma00045a034

[78] Hossain, D., Tschopp, M.A., Ward, D.K., Bouvard, J.L., Wang, P. and Horstemeyer, M.F. (2010) Molecular Dynamics Simulations of Deformation Mechanisms of Amorphous Polyethylene. Polymer, 51, 6071-6083. https://doi.org/10.1016/j.polymer.2010.10.009

[79] Tschopp, M.A., Ward, D.K., Bouvard, J.L. and Horstemeyer, M.F. (2011) Atomic Scale Deformation Mechanisms of Amorphous Polyethylene under Tensile Loading. TMS Conference Proceedings, Vol. 2, 1-6. https://doi.org/10.1002/9781118062142.ch95

[80] Plimpton, S. (1995) Fast Parallel Algorithms for Short-Range Molecular Dynamics. Journal of Computational Physics, 117, 1-19. https://doi.org/10.1006/jcph.1995.1039

[81] Bouvard, J.L., Ward, D., Hossain, D., Marin, E.B. and Horstemeyer, M.F. (2009) Review of Hierarchical Multiscale Modeling to Describe the Mechanical Behavior of Amorphous Polymers. JEMT, Special Issue: Predictive Science \& Technology in Mechanics \& Materials, 131, Article ID: 041206. https://doi.org/10.1115/1.3183779

[82] Han, J., Gee, R.H. and Boyd, R.H. (1994) Glass Transition Temperatures of Polymers from Molecular Dynamics Simulations. Macromolecules, 27, 7781-7784. https://doi.org/10.1021/ma00104a036

[83] Gee, R.H. and Boyd, R.H. (1998) The Role of the Torsional Potential in Relaxation Dynamics: A Molecular Dynamics Study of Polyethylene. Computational and Theoretical Polymer Science, 8, 93-98. https://doi.org/10.1016/S1089-3156(98)00020-8

[84] Mayo, S.L., Olafson, B.D. and Goddard III, W.A. (1990) DREIDING: A Generic Force Field for Molecular Simulations. The Journal of Physical Chemistry, 94, 8897-8909. https://doi.org/10.1021/j100389a010

[85] Capaldi, F.M., Boyce, M.C. and Rutledge, G.C. (2001) Enhanced Mobility Accompanies the Active Deformation of a Glassy Amorphous Polymer. Physical Review Letters, 89, Article ID: 175505. https://doi.org/10.1103/PhysRevLett.89.175505

[86] Tschopp, M.A., Bouvard, J.L., Ward, D.K., Bammann, D.J. and Horstemeyer, M.F. (2013) Influence of Ensemble Boundary Conditions (Thermostat and Barostat) on the Deformation of Amorphous Polyethylene by Molecular Dynamics.

[87] Shepherd, J.E., McDowell, D.L. and Jacob, K.I. (2006) Modeling Morphology Evolution and Mechanical Behavior during Thermo-Mechanical Processing of SemiCrystalline Polymers. Journal of the Mechanics and Physics of Solids, 54, 467-489. https://doi.org/10.1016/j.jmps.2005.10.003

[88] Shepherd, J.E. (2006) Multiscale Modeling of the Deformation of Semi-Crystalline Polymers. PhD Thesis, Georgia Institute of Technology, Atlanta.

[89] Brandrup, J. and Immergut, E.H. (1989) Polymer Handbook. 3rd Edition, Wiley-Interscience, New York.

[90] Plimpton, S.J. (1995) Fast Parallel Algorithms for Short-Range Molecular Dynamics. Computational Physics, 117, 1-19. https://doi.org/10.1006/jcph.1995.1039

[91] Melchionna, S., Ciccotti, G. and Holian, B.L. (1993) Hoover NPT Dynamics for Systems Varying in Shape and Size. Molecular Physics, 78, 533-544. https://doi.org/10.1080/00268979300100371

[92] Nosé, S.J. (1984) A Unified Formulation of the Constant Temperature Molecular Dynamics Methods. Chemical Physics, 81, 511-519.

https://doi.org/10.1063/1.447334 
[93] Hoover, W.G. (1985) Canonical Dynamics: Equilibrium Phase-Space Distributions. Physical Review A, 31, 1695-1697. https://doi.org/10.1103/PhysRevA.31.1695

[94] Lyubartsev, A. (2005) Multiscale Modeling of Lipids and Lipid Bilayers. European Biophysics Journal, 35, 53-61. https://doi.org/10.1007/s00249-005-0005-y

[95] Keener, T.J., Stuart, R.K. and Brown, T.K. (2004) Maleated Coupling Agents for Natural Fibre Composites. Composite Part A, 35, 357-362. https://doi.org/10.1016/j.compositesa.2003.09.014

[96] Li, Q. and Matuana, L.M. (2003) Effectiveness of Maleated and Acrylic Acid-Functionalized Polyolefin Coupling Agents for HDPE-Wood-Flour Composites. Journal of Thermoplastic Composite Materials, 16, 551-564. https://doi.org/10.1177/089270503033340

[97] Lu, J.Z., Wu, Q. and Negulescu, H. (2000) The Influence of Maleation on Polymer Adsorption and Fixation, Wood Surface Wettability, and Interfacial Bonding Strength in Wood-PVC Composites. Wood and Fiber Science, 34, 434-459.

[98] Wang, Y.E.H., Yeh, F.C., Lai, S.M., Chan, H.C. and Shen, H.F. (2003) Effectiveness of Functionalized Polyolefins as Compatibilizers for Polyethylene/Wood Flour Composites. Polymer Engineering \& Science, 43, 933-945.

https://doi.org/10.1002/pen.10077

[99] Balasuriya, P.W., Ye, L., Mai, Y.W. and Wu, J. (2002) Mechanical Properties of Wood Flake-Polyethylene Composites II. Interface Modification. Journal of Applied Polymer Science, 83, 2505-2521. https://doi.org/10.1002/app.10189

[100] Tsuzuki, H., Branicio, P.S. and Rino, J.P. (2007) Structural Characterization of Deformed Crystals by Analysis of Common Atomic Neighborhood. Computer Physics Communications, 177, 518-523. https://doi.org/10.1016/j.cpc.2007.05.018

[101] Sankaranarayanan, S.K.R.S., Bhethanabotla, V.R. and Joseph, B. (2005) Molecular Dynamics Simulation Study of the Melting of Pd-Pt Nanoclusters. Physical Review B, 71, Article ID: 195415. https://doi.org/10.1103/PhysRevB.71.195415

[102] Honeycutt, J.D. and Andersen, H.C. (1987) Molecular Dynamics Study of Melting and Freezing of Small Lennard-Jones Clusters. The Journal of Physical Chemistry, 91, 4950-4963. https://doi.org/10.1021/j100303a014 